\title{
Hellenic Association for the Study of the Liver Clinical Practice Guidelines: Autoimmune hepatitis
}

\author{
George N. Dalekos ${ }^{\mathrm{a}, \mathrm{b}}$, John Koskinas ${ }^{c}$, George V. Papatheodoridis ${ }^{\mathrm{d}}$ \\ Institute of Internal Medicine and Hepatology, Larissa; University Hospital of Larissa; National and Kapodistrian \\ University of Athens, "Hippokratio" General Hospital of Athens, Athens; Medical School of National and Kapodistrian \\ University of Athens, "Laiko" General Hospital of Athens, Athens, Greece
}

Abstract

${ }^{a}$ Institute of Internal Medicine and Hepatology, Larissa

(George N. Dalekos); ${ }^{b}$ Department of Medicine and Research Laboratory of Internal Medicine, University Hospital of Larissa, Larissa (George N. Dalekos); 'Second Department of Internal Medicine, National and Kapodistrian University of Athens, "Hippokratio" General Hospital of Athens, Athens (John Koskinas); 'Department of Gastroenterology, Medical School of National and Kapodistrian University of Athens, "Laiko" General Hospital of Athens, Athens (George V. Papatheodoridis), Greece

\section{Conflict of Interest: None}

Correspondence to: George N. Dalekos, MD, PhD, Professor of Medicine, Institute of Internal Medicine and Hepatology, Head, Department of Medicine and Research Laboratory of Internal Medicine, University Hospital of Larissa, 41110 Larissa, Greece, e-mail: georgedalekos@gmail.com

Received 1 September 2018; accepted 29 October 2018; published online 29 November 2018

DOI: https://doi.org/10.20524/aog.2018.0330

\section{Introduction and historical review}

In 1950, Jan Waldenström was the first to describe a new type of a progressive, usually fatal, chronic hepatitis in young females with endocrine dysfunction, cutaneous striae, acne, polyarthralgias, and high $\gamma$-globulins that correlated with abundant plasma cells on liver biopsy [1]. In 1956, Cowling et al [2] introduced the term "lupoid hepatitis", because the lupus erythematosus cell phenomenon was observed in these patients. However, 10 years later, this term was changed to "autoimmune hepatitis" (AIH), finally accepted by the International AIH Group (IAIHG) as the definite one $[3,4]$.

The aim of the present Clinical Practice Guidelines (CPG) of the Hellenic Association for the Study of the Liver (HASL) was to provide guidance and help to gastroenterologists, hepatologists, internists and general practitioners in the diagnosis and management of this disease, in an attempt to improve care for affected patients. The current statements 
and recommendations were based on the GRADE system for evidence published by Shaneyfelt et al [5] (Suppl. Table 1).

\section{Epidemiology}

$\mathrm{AIH}$ is an acute or more frequently chronic liver disease of unknown etiology that primarily affects females (female/male: 3-4/1) and is characterized by polyclonal hypergammaglobulinemia, particularly of immunoglobulin G (IgG), autoantibodies, interface hepatitis and favorable response to treatment [6-10].

$\mathrm{AIH}$ is considered relatively rare, as its prevalence is about 160-180/1,000,000 population in Europe [11-14]. Recently, a large nationwide study in Denmark showed a significant increase in $\mathrm{AIH}$ incidence, reaching a prevalence of $350 / 1,000,000$ in women [15]. So far, reliable epidemiological data from Greece are not available; therefore, since 2016 HASL has started a nationwide registry for all retro- and prospective AIH cases.

AIH carries several clinical phenotypes and outcomes according to ethnicity, with patients of Hispanic, Asian or other non-European Caucasian origin demonstrating poor outcomes [16]. These differences are thought to be due to differences in genetic predisposition and triggering agents, but also to complex socioeconomic factors, such as discrepancies in healthcare delivery and failure to diagnose $\mathrm{AIH}$, which finally results in delayed diagnosis [17].

\section{STATEMENT 1}

- AIH prevalence is increasing in Europe irrespective of sex, ranging from 160-180/1,000,000 inhabitants to as much as $350 / 1,000,000$ in females (II-2)

\section{Clinical manifestations}

\section{Clinical characteristics}

$\mathrm{AIH}$ is a discrete clinical syndrome characterized by considerable demographic, clinical, laboratory and histological heterogeneity (Table 1). Therefore, extended differential diagnosis should be performed, considering the possibility of AIH in any acute or chronic liver disease (Tables 2, 3) [4,6-8,10,18-22]. Both sexes in all ethnic groups can be affected at any age. Disease onset has a bimodal distribution during the childhood/teenage and $4^{\text {th }}-6^{\text {th }}$ decades, but recently many patients have been diagnosed at older ages (>65 years) [6-8,11-15,23-25]. The disease may accumulate in first-degree relatives, but the absolute risk is very low. High rates of depression and anxiety have recently been recognized in AIH patients [26,27].

The manifestations are variable, ranging from asymptomatic to acute/severe or even fulminant hepatitis

$\underline{\text { Table } 1 \text { Clinical manifestations of autoimmune hepatitis (AIH) }}$

Characteristic

\begin{tabular}{|c|c|}
\hline Age at presentation & $\begin{array}{l}\text { Any age in both sexes (F/M: } 3-4 / 1) \text { and all ethnic groups can be affected; bimodal distribution with usual peaks in } \\
\text { puberty and } 4^{\text {th }}-6^{\text {th }} \text { decades; a substantial proportion of patients, however, are older ( }>65 \text { years) }\end{array}$ \\
\hline Disease onset & $\begin{array}{l}\text { From asymptomatic to acute/severe or even fulminant hepatitis } \\
\text { Two thirds of patients present either without any symptom or with an insidious onset (one or more of the following } \\
\text { unspecific symptoms: malaise, fatigue, amenorrhea, general ill health, lethargy, anorexia, right upper quadrant pain, } \\
\text { weight loss, nausea, jaundice and arthralgias usually involving the small joints, sometimes dating back years) } \\
\text { Acute AIH in } 25-40 \% \text { of patients, presenting either as an acute worsening of chronic AIH or as real acute AIH without } \\
\text { findings of chronic disease on liver histology; absence of autoantibodies detection or other usual features is not } \\
\text { surprising; response to corticosteroids variable } \\
\text { At diagnosis } 1 / 3 \text { of patients already have cirrhosis, regardless of the presence or absence of symptoms, suggesting a delay } \\
\text { in diagnosis }\end{array}$ \\
\hline Classification & $\begin{array}{l}\text { AIH-1: the more frequent type ( } 90 \% \text { of cases); ANA, SMA or anti-SLA/LP reactivity (the latter often with anti-Ro52 } \\
\text { reactivity; potentially more severe); association with HLA DR3, DR4 and DR13; rare treatment failure but variable relapse } \\
\text { rates after complete drug cessation and variable need for long-term maintenance therapy } \\
\text { AIH-2: approximately } 10 \% \text { of cases; anti-LKM1, anti-LC1 and rarely anti-LKM3 reactivity; association with HLA DR3 } \\
\text { and DR7; onset usually in childhood and young adulthood; from the clinical and histological points of view this type is } \\
\text { usually more acute and advanced; frequent treatment failure and frequent relapses after complete drug discontinuation; } \\
\text { need for long-term maintenance therapy very common }\end{array}$ \\
\hline Physical findings & From completely normal to signs of chronic liver disease and/or portal hypertension \\
\hline Complications & $\begin{array}{l}\text { HCC rates are significantly lower than in other liver diseases, but it does exist in association with underlying cirrhosis, } \\
\text { suggesting surveillance in all AIH-related cirrhotics } \\
\text { Significant treatment-related side-effects are found in } 15-25 \% \text { of patients (most commonly related with long-term } \\
\text { corticosteroid use or toxicity and/or intolerance of azathioprine) }\end{array}$ \\
\hline
\end{tabular}

F, female; M, male; ANA, antinuclear antibodies; SMA, smooth muscle antibodies; anti-SLA/LP, antibodies against soluble liver antigens/liver pancreas; HLA, human leukocyte antigens; anti-LKM1, anti-liver/kidney microsomal antibody type-1; anti-LC1, antibodies against liver cytosol type-1 antigen; anti-LKM3, antiliver/kidney microsomal antibody type-3; HCC, hepatocellular carcinoma 
Table 2 Differential diagnosis of autoimmune hepatitis

\begin{tabular}{l}
\hline Acute or chronic viral hepatitis A, B, C, D, E \\
Drug-induced liver injury \\
Alcoholic liver disease \\
PBC, PSC, AIH/PBC variant, AIH/PSC variant \\
Wilson's disease \\
Non-alcoholic fatty liver/steatohepatitis \\
Hemochromatosis \\
a1-antitrypsin deficiency \\
Celiac disease \\
\hline PBC, primary biliary cholangitis; $P S C$, primary sclerosing cholangitis; $A I H$, \\
autoimmune hepatitis
\end{tabular}

Table 3 Common concurrent autoimmune or immune-mediated diseases in patients with autoimmune hepatitis

\begin{tabular}{l}
\hline Hashimoto thyroiditis - the strongest association \\
Grave's disease \\
Vitiligo, alopecia, psoriasis \\
Rheumatoid arthritis \\
Diabetes mellitus type 1 \\
Inflammatory bowel disease \\
Systemic lupus erythematosus \\
Sjögren's syndrome \\
Celiac disease \\
Panniculitis, mononeuritis, urticaria pigmentosa, Sweet's syndrome, \\
idiopathic thrombocytopenic purpura, polymyositis, hemolytic \\
anemia, uveitis \\
Autoimmune polyendocrinopathy-candidiasis ectodermal \\
dystrophy syndrome also known as autoimmune \\
polyendocrinopathy syndrome-type 1
\end{tabular}

(Table 1) [7-9,28-30]. The acute onset accounts for $25-40 \%$ of patients and does not differ from other causes of acute hepatitis [29-31]. Two different syndromes are recognized in acute AIH: one is the acute worsening of a previously undiagnosed or misdiagnosed chronic AIH and the second is the original acute disease without chronic lesions on histology (Table 1) [28,31,32]. Interestingly, some patients with acute AIH have normal IgG levels, while $9-17 \%$ of patients have negative results at first screening for antinuclear (ANA) or smooth muscle (SMA) antibodies; consequently, physicians may not consider AIH [6-10].

Two thirds of patients present either without any symptom or with an insidious onset characterized by one or more of the general non-specific symptoms shown in Table 1 [11,14-17,23,33,34]. Physical findings vary from completely normal to signs of advanced disease with accompanied portal hypertension. Unfortunately, almost one third of adults and half of children already have cirrhosis at diagnosis [11,15,23,33-36].

According to the autoantibodies detected, a classification of AIH into two major types, $\mathrm{AIH}-1$ and $\mathrm{AIH}-2$, has been introduced (Table 1). AIH-1 is characterized by ANA, SMA and/or soluble liver antigens/liver pancreas antibodies (anti-
SLA/LP) detection, while AIH-2 is associated with anti-liver/ kidney microsomal antibody type-1 (anti-LKM1), or rarely anti-LKM-type 3 (anti-LKM3), and/or antibodies against liver cytosol type-1 antigen (anti-LC1) [6,7,10,18,19]. Apart from autoantibodies, this distinction also brings other differences helpful for clinicians (Table 1).

\section{RECOMMENDATIONS 1-6}

- AIH should be considered in any patient with acute or chronic hepatitis, particularly in the presence of high IgG levels, as it has a global distribution at any age in both sexes and in all ethnic groups (II-2)

- Precise and early diagnosis is mandatory, as untreated AIH carries high morbidity and mortality rates (I)

- AIH patients can be considered for screening for concurrent autoimmune diseases, especially autoimmune thyroiditis, since AIH is associated with a reduced quality of life and a broad variety of other autoimmune-mediated conditions (II-2)

- Cirrhosis at diagnosis should be suspected in AIH, as almost $33 \%$ of adults and $50 \%$ of children with $\mathrm{AIH}$ are first diagnosed at the stage of cirrhosis, indicating that they have had subclinical disease for a long time (II-2)

- Acute AIH can be diagnosed presenting as one of the following two clinical forms:

- acute worsening of previously undiagnosed or misdiagnosed AIH or

- real (original) acute onset of AIH without chronic lesions on liver histology (II-2)

- AIH can be classified into two types: AIH-1, ANA, SMA and/or anti-SLA/LP positive; and AIH-2, antiLKM1, anti-LKM3 and/or anti-LC1 positive. Apart from differences in circulating autoantibodies, other differences in the clinical substrate have become apparent that may be helpful to clinicians (II-2)

\section{Specific features}

AIH may be first diagnosed during pregnancy or more frequently after delivery (Table 4). Postpartum exacerbations may also occur in AIH patients whose condition improved during pregnancy [37-39]. Interestingly, immunosuppression has probably enabled the occurrence of pregnancy in young females with amenorrhea at presentation due to AIH.

AIH may also develop after the administration of many drugs, supplements and/or herbals, with nitrofurantoin and minocycline being the best documented among diverse cases (Table 4) [40-44]. Drug-induced AIH is a complex and challenging condition characterized clinically and histologically by different phenotypes across the disease spectrum $[40,45]$. Therefore, the differentiation between drug-induced liver 
injury (DILI) and DILI-induced AIH is often difficult [46]. In such cases, the patients' history is important, as in one third of patients with DILI the clinical features can be associated with hypersensitivity manifestations, such as fever, rash and eosinophilia $[47,48]$. The follow up can also help in differential diagnosis, as steroid treatment can be discontinued without

Table 4 Specific characteristics of autoimmune hepatitis (AIH)

Characteristic

\begin{tabular}{|c|c|}
\hline Special conditions & $\begin{array}{l}\text { Development of AIH in pregnant women or more frequently in the postpartum period is a rare event but does occur; } \\
\text { the disease lessens during pregnancy but postpartum worsening is common; maternal and pregnancy outcomes are } \\
\text { similar to those of the general population } \\
\text { AIH development after liver transplantation for conditions other than AIH (de novo AIH) } \\
\text { Some AIH patients have PBC or PSC characteristics (AIH-PBC or AIH-PSC variants); in case of cholestatic findings, } \\
\text { AMA investigation and cholangiography (particularly in children - autoimmune sclerosing cholangitis) are advised; } \\
\text { "Paris criteria" for AIH-PBC variant: presence of at least } 2 / 3 \text { key criteria of each disease; for PBC: } 1 \text { ) ALP } \geq 2 \times \text { ULN } \\
\text { or } \gamma \text {-GT } \geq 5 \times \text { ULN, } 2 \text { ) AMA detection, } 3 \text { ) liver biopsy showing florid bile duct lesions; for AIH: } 1 \text { ) ALT } \geq 5 \times \text { ULN, } 2 \text { ) } \\
\text { IgG } \geq 2 \times \text { ULN or SMA detection, } 3 \text { ) liver biopsy showing moderate or severe periportal or periseptal lymphocytic } \\
\text { piecemeal necrosis; IAIHG scoring systems should not be used to define such patients }\end{array}$ \\
\hline Specific characteristics & $\begin{array}{l}\text { AIH development after use of drugs, supplements or herbals with nitrofurantoin and minocycline implicated in most } \\
\text { cases; other drugs include: oxyphenisatin, ornidazole, methyldopa, diclofenac, interferon-a, atorvastatin, liraglutide, } \\
\text { highly active antiretroviral treatment for human immunodeficiency virus and biologics including TNFa blockade } \\
\text { agents; often very difficult to differentiate from DILI } \\
\text { AIH development after viral infections (e.g., Epstein-Barr, cytomegalovirus) including HCV; AIH should be strongly } \\
\text { taken into account in cases with previous documented viral infections followed by unidentified and prolonged } \\
\text { elevation of aminotransferases }\end{array}$ \\
\hline
\end{tabular}

PBC, primary biliary cholangitis; $P S C$, primary sclerosing cholangitis; AMA, antimitochondrial antibodies; ALP, alkaline phosphatase; $\gamma$-GT, $\gamma$-glutamyltranspeptidase; ALT, alanine aminotransferase; IgG, immunoglobulin G, SMA, smooth muscle antibodies; IAIHG, International autoimmune hepatitis group; TNFa, tumor necrosis factor alpha; DILI, drug induced liver injury; HCV, hepatitis C virus; ULN, upper limit of normal

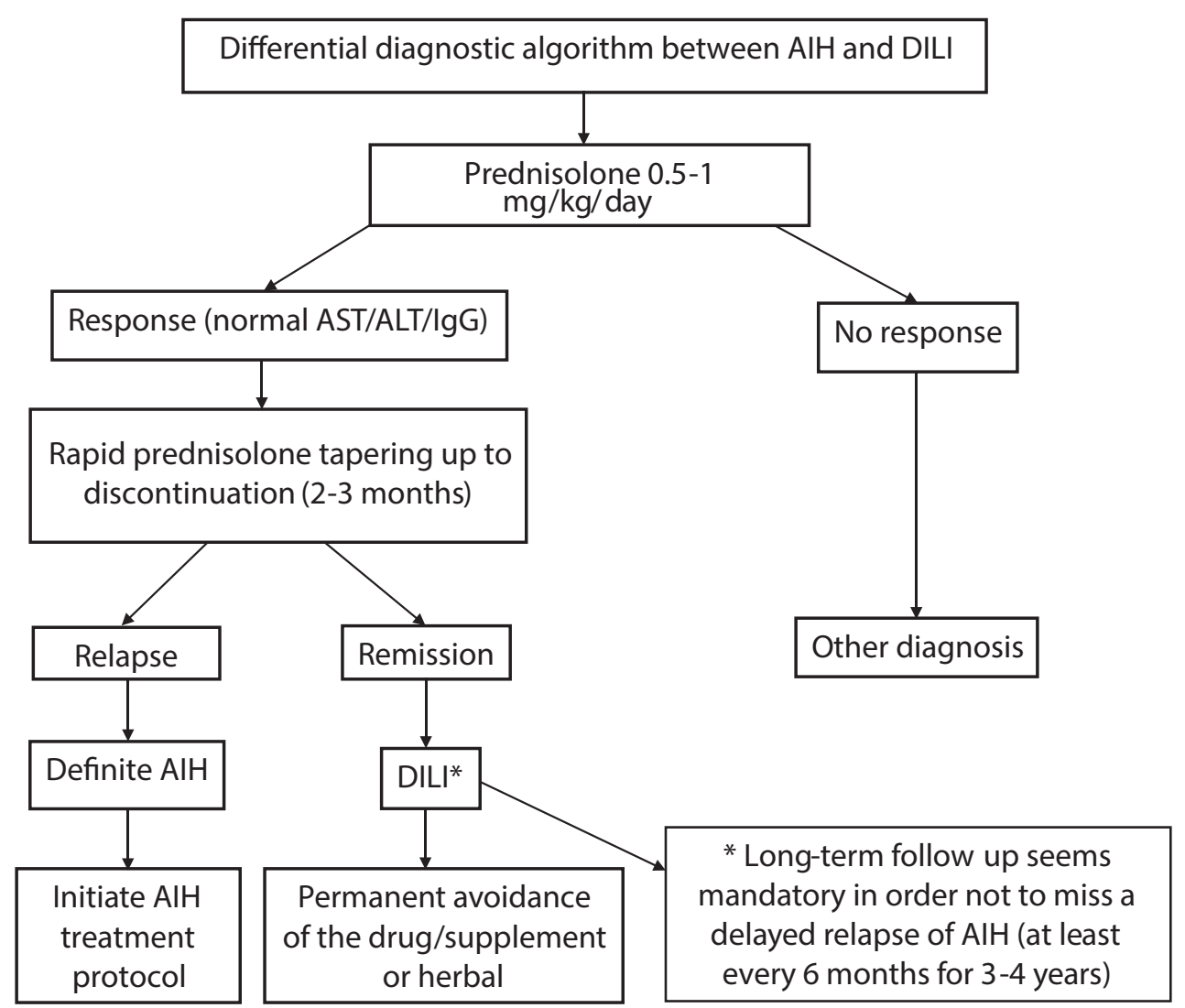

Figure 1 Proposed algorithm for the differential diagnosis between autoimmune hepatitis (AIH) and drug-induced liver injury (DILI) in an index case with biochemical hepatitis, positive liver autoimmune serology and hepatitis on liver histology, irrespective of the presence or absence of high IgG levels

AST, aspartate aminotransferase; ALT, alanine aminotransferase; IgG, immunoglobulin G 
relapse in DILI, in contrast to the almost universal relapse after stopping a few-month course of immunosuppressive therapy in the "true" DILI-induced AIH (Fig. 1).

AIH development has also been observed after viral infections $[7,8,49,50]$, including hepatitis $\mathrm{C}$ virus ( $\mathrm{HCV}$ ) treated with interferon-a (IFNa) [51], or after liver transplantation for other liver diseases in adults and children (Table 4). This condition has been called de novo AIH and its early recognition seems helpful for avoiding another liver transplantation and improving patients' long-term survival [52-54].

\section{RECOMMENDATION 7}

- AIH should be considered in the appropriate clinical and laboratory setting after use of drugs, supplements or herbals; viral infections; liver transplantation (de novo $\mathrm{AIH}$ ); and rarely during pregnancy or after delivery (II-3)

\section{Complications}

As in other chronic liver diseases, cirrhosis and its consequences, including portal hypertension and hepatocellular carcinoma (HCC), may occur. Therefore, surveillance with ultrasonography every 6 months seems rational in patients with cirrhosis. HCC, however, is developed at significantly lower rates in $\mathrm{AIH}$-associated cirrhosis compared with other causes (Table 1) [14,15,55-58].

\section{RECOMMENDATION 8}

- Patients with AIH-related cirrhosis should undergo ultrasonography every 6 months for early HCC detection, as in cirrhosis of other etiologies (II-2)

\section{AlH variants}

Some patients present, either concurrently or consecutively, with features of primary biliary cholangitis (PBC) or primary sclerosing cholangitis (PSC), while some PBC or PSC patients may also show AIH characteristics (Table 4) [59]. However, the previous term "overlap" used for years for these entities strongly suggests the simultaneous presence of two distinct diseases, which of course is not the case for many of these patients. Therefore, the term "variant" has recently been proposed by the European Association for the Study of the Liver (EASL), thought to be more precise for these conditions [60].

Worldwide accepted criteria defining these conditions are lacking and hence their diagnosis is usually difficult. Regarding the AIH-PBC variant, its prevalence is about $10 \%$ in adults with $\mathrm{PBC}$ or AIH [61]. The "Paris criteria" are even nowadays the most often used in everyday clinical practice (Table 4) [61]. Unlike several uncertainties around this issue, the recent EASL guidelines on $\mathrm{PBC}$ diagnosis and management recommend that liver histology is mandatory in evaluating patients with this variant of AIH [62]. In particular, liver biopsy seems crucial because of potential therapeutic implications in the PBC cases who do not respond to ursodeoxycholic acid (UDCA), having also disproportionate elevations in alanine aminotransferase (ALT) and/or IgG [62].

The AIH-PSC variant has been reported in $7-14 \%$ of mainly young patients with autoimmune liver diseases [59,63-65]. The criteria for AIH-PSC diagnosis are even less well defined than those used in AIH-PBC patients. In routine clinical practice, AIH-PSC diagnosis is based on typical cholangiographic or histological characteristics of PSC, along with AIH characteristics [66]. Interestingly, a specific and unique variant has been reported in $50 \%$ of children with $\mathrm{AIH}$, characterized by both AIH and sclerosing cholangitis features; therefore, the term "autoimmune sclerosing cholangitis" was proposed [63]. Magnetic resonance cholangiopancreatography (MRCP) is advised for all children with an initial AIH diagnosis (Table 4) $[63,64]$. This entity is exceptionally rare in adults with $\mathrm{AIH}$ and thus MRCP screening is not justified [67].

\section{STATEMENT 2}

- Coexistence of AIH features and cholestatic diseases can be observed at both diagnosis and follow up, but their diagnosis may be problematic because of the lack of internationally accepted criteria (II-2)

\section{RECOMMENDATIONS 9-11}

- All children with AIH should undergo at least MRCP to exclude autoimmune sclerosing cholangitis (II-2)

- Adult AIH patients should be considered for MRCP only when cholestatic laboratory manifestations are present (II-3)

- AIH patients showing cholestatic features should be tested for PBC (II-2)

\section{Laboratory investigation}

\section{Biochemistry}

Bilirubin and aminotransferase levels vary from just above the upper limits of normal (ULN) to very high levels $[4,7,8,18,19]$. Alkaline phosphatase (ALP) is usually normal or moderately elevated, while $\gamma$-glutamyl-transpeptidase $(\gamma-G T)$ can increase variously $[23,34]$. Spontaneous normalization of aminotransferases and $\gamma$-GT can be observed, although there is usually evidence of continuing inflammatory activity at the histological level. This phenomenon may result 
in delay and/or underestimation of AIH diagnosis, as the next AIH hit can be pronounced after many months or years or may even be absolutely asymptomatic, explaining at least partially the presence of cirrhosis in one third of patients at diagnosis.

Irrespectively of the presence of cirrhosis, the majority of patients have high serum $\gamma$-globulins or IgG, a distinctive feature of AIH [19,23]. However, 25-40\% of patients with acute AIH have normal IgG $[29,68]$. It should be noted that the range of "normal" IgG is ample, as it is impractical to have the "real normal ranges" of the respective population where an index case resides.

\section{Liver autoimmune serology}

\section{Conventional antibodies}

Autoantibodies are the hallmark for AIH diagnosis. Indirect immunofluorescence (IIF), preferably on freshly frozen rodent substrates including kidney, liver and stomach, is the technique of choice for routine screening (Fig. 2) [60]. Significant titers are $\geq 1: 40$ in adults, while $\geq 1: 20$ for ANA or SMA and $\geq 1: 10$ for antiLKM1 are supportive of AIH diagnosis in children in association with other laboratory and clinical findings $[19,60,69]$. Other assays, such as ELISA or immunoblotting, are available for antiLKM1, anti-LKM3, anti-LC1 and anti-SLA/LP testing $[7,8,70]$.

ANA and SMA are not disease-specific and show a wide range of heterogeneity in the IIF pattern on HEp2 cells, together with varying titers $[7,8,60]$. However, no single ANA staining pattern on HEp2 cells is pathognomonic of AIH or seems to have any clinical and diagnostic implication in everyday practice; for these reasons their use in initial testing is not recommended. Since SMA react to cytoskeletal elements, including F-actin (the major autoantigen of SMA), testing for anti-F-actin antibodies can also be performed by ELISA [7,8,71,72]. However, IIF appears superior compared with ELISA, as testing only by ELISA may result in missing almost $20 \%$ of AIH cases [7,8,71-73].

Anti-LKM1/3 and/or anti-LC1 often coexist in AIH-2 but are not disease-specific, as they may be detected in $5-10 \%$ of $\mathrm{HCV}$ or hepatitis D virus (HDV) infections [7,8,23,51,70-72,74-76]. The major target-autoantigens of anti-LKM1 and anti-LKM3, first described in about $13 \%$ of HDV infections, are the cytochrome P4502D6 and family-1 of UDP-glucuronosyltransferases, respectively-although the antigenic sites differ between $\mathrm{AIH}$ and HCV or HDV infections; for anti-LC1 the major targetautoantigen is the formiminotransferase cyclodeaminase enzyme [7,8,60,70-72,74,76,77]. Repeated testing is advised in initially seronegative individuals, as conventional autoantibody titers vary during the course of $\mathrm{AIH}$ and may be detected later [18,70-72]. Autoantibody titers do not need to be monitored in adults, but should be in children, where they are considered as markers of disease activity [69]. Notably, the previous recommendation of the IAIHG for anti-LKM screening before starting IFNa-based therapies in HCV infections, as IFNa may sometimes unmask or provoke autoimmune liver reactivity and even original $\mathrm{AIH}$, seems not to be rational in the new era of direct acting antivirals (DAAs) [18,51,65,78].

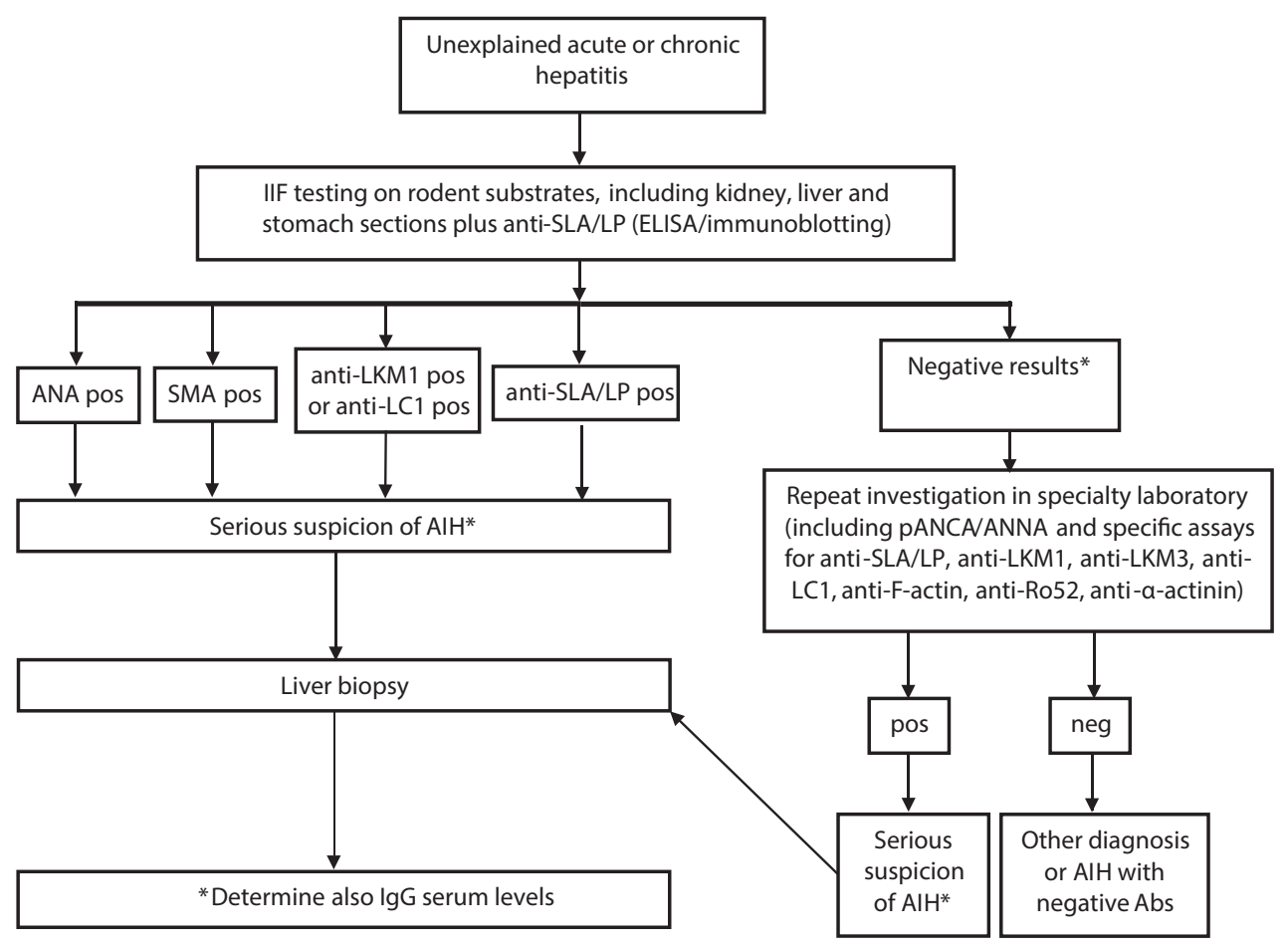

Figure 2 Proposed algorithm for routine autoantibody testing in cases with a suspicion of autoimmune hepatitis

Anti-SLA/LP, antibodies against soluble liver antigens/liver pancreas; ELISA, enzyme linked immunosorbent assay; Abs, autoantibodies; ANA, antinuclear antibodies; SMA, smooth muscle antibodies; anti-LKM1, anti-liver/kidney microsomal antibody type 1; anti-LC1, antibodies against liver cytosol type-1 antigen; pANCA/ANNA, perinuclear anti-neutrophil cytoplasmic antibodies/anti-nuclear neutrophil antibodies; anti-LKM3, anti-liver/ kidney microsomal antibody type 3; AIH, autoimmune hepatitis 


\section{Non-conventional antibodies}

Anti-SLA/LP has greater diagnostic value, being the only AIH-specific autoantibody. However, it is only detected in up to a third of patients, usually in strong association with antiRo52 antibodies (concurrence in 77-98\%) [79-82]. The targetautoantigen is a synthase $(\mathrm{S})$ converting $O$-phosphoseryl-tRNA (Sep) to selenocysteinyl-tRNA (Sec); it is therefore labeled as SepSecS, which in turn resulted in the development of reliable molecular-based assays for its detection $[83,84]$. Anti-SLA/LP has been associated with more aggressive disease [85], although these findings were not confirmed in recent studies [79,82].

Perinuclear pattern of anti-neutrophil cytoplasmic antibodies (pANCA), also referred to as perinuclear anti-neutrophil nuclear antibodies (p-ANNA), are detected (significant titer $\geq 1: 20$ ) by IIF frequently in AIH-1 patients and may act as an additional pointer towards diagnosis [18,69-72]. Anti-mitochondrial antibodies (AMA), strongly specific for PBC [86], can be detected in $8-12 \%$ of $\mathrm{AIH}$ patients without, however, any other evidence of chronic cholestatic disease [87-92].

Antibodies against $\alpha$-actinin, which belongs to the F-actin cross-linking proteins, have been detected in autoimmune diseases such as systemiclupus erythematosus and AIH-1 [93,94]. These antibodies seem to carry particular clinical significance, as they characterize a subgroup of more severe form of $\mathrm{AIH}$, specifically in association with anti-F-actin, while they might be used as predictors of treatment response [95-97]. Antibody against the asialoglycoprotein receptor is another frequently detected autoantibody, which can support diagnosis if patients have tested negative for other autoantibodies [7,8,70-72]. However, its specificity seems low and therefore its routine determination is not recommended [60].

\section{Liver histology}

The presence of hepatitis is a prerequisite for AIH diagnosis $[4,6,10,18,19,60]$. Ideally, liver biopsy should be performed before the initiation of treatment, as disease necroinflammatory activity and severity are not always in parallel with biochemistry $[6,10,18,19]$. Therefore, a pretreatment liver biopsy can provide information on prognosis but also on optimal AIH management; for instance, the potential presence of cirrhosis may influence the choice and dose of immunosuppression and suggest regular screening for complications. The typical lesions consist of interface hepatitis with portal lymphocytic/lymphoplasmacytic cells extending into lobule, hepatocyte rosetting and emperipolesis (etymology from the Greek language), which refers to the intracytoplasmic localization of one cell, usually a lymphocyte, within hepatocytes [19]. It should be noted however, that the abovementioned findings are not pathognomonic for $\mathrm{AIH}$, while the absence of plasma cells observed in almost one third of $\mathrm{AIH}$ cases does not rule out the diagnosis [98].

Biopsies performed early in the acute disease show several signs of severe inflammatory activity, such as panlobular hepatitis with parenchymal collapse, presence of portal lymphoid follicles, inflammatory infiltrates enriched by plasma cells, central perivenulitis and pericentral, bridging or massive necrosis resembling those observed in acute DILI $[18,28,68,99]$. Inflammatory lymphocytic infiltrates of bile ducts have also been reported in approximately $10 \%$ of patients-without, however, any other clear manifestation of PBC [100]. At presentation, various fibrosis stages may be seen. Quantitative evaluation of inflammatory activity using the hepatitis activity index (HAI) score seems helpful during therapy and follow up.

Concerning the noninvasive methods, and in particular liver elastography, a recent study established that repeat transient elastography measurement is a reliable tool for AIH monitoring [101]. At present, however, the general belief is that the noninvasive tests are not able to replace liver biopsy at diagnosis and before treatment discontinuation [102].

\section{Differential diagnosis and diagnostic scores}

The differential diagnosis includes almost all causes of acute and chronic liver diseases as well as celiac disease $[8,72,103]$ (Table 2). In 1999, the IAIHG published a score for AIH

\section{STATEMENTS 3-5}

- $\mathrm{AIH}$ is a clinicopathological diagnosis and relies mainly on autoantibody detection, polyclonal hypergammaglobulinemia and supporting histology, usually in the absence of other liver disease (II-2)

- Aminotransferases and bilirubin values vary in AIH (II-2)

- Presence of hepatitis at the histological level is a prerequisite for diagnosis (II-2)

\section{RECOMMENDATIONS 12-16}

- Normal IgG should not exclude the diagnosis of $\mathrm{AIH}$, even though a selective high serum IgG is an important AIH characteristic (II-3)

- IIF, preferably on freshly frozen rodent substrates, should be used for routine screening in the detection of most autoantibodies, while ELISA and immunoblotting should be used as the tests for antiSLA/LP and anti-LC1 (II-3)

- No anti-LKM screening is nowadays required in HCV patients before DAAs therapy (III)

- Interface hepatitis, hepatocyte rosetting and emperipolesis should be considered as strongly supportive, although not pathognomonic, of AIH (II-2)

- In acute AIH, several histological signs of severe inflammatory activity are observed, but they are usually indistinguishable from DILI (II-3) 
Table 5 Revised scoring system for autoimmune hepatitis diagnosis (adapted from [18])

\begin{tabular}{|c|c|}
\hline Parameter/Features & Score \\
\hline Sex: Female/Male & $+2 / 0$ \\
\hline \multicolumn{2}{|l|}{$\begin{array}{l}\text { Degree of elevation above ULN of alkaline } \\
\text { phosphatase vs. aminotransferases }\end{array}$} \\
\hline$<1.5$ & +2 \\
\hline $1.5-3.0$ & 0 \\
\hline$>3.0$ & -2 \\
\hline \multicolumn{2}{|l|}{ Total serum globulins, $\gamma$-globulins, or IgG above normal } \\
\hline$>2.0$ & +3 \\
\hline $1.5-2.0$ & +2 \\
\hline $1.0-1.5$ & +1 \\
\hline$<1.0$ & 0 \\
\hline \multicolumn{2}{|l|}{ ANA, SMA or LKM-1 titers by immunofluorescence } \\
\hline$>1: 80$ & +3 \\
\hline $1: 80$ & +2 \\
\hline $1: 40$ & +1 \\
\hline$<1: 40$ & 0 \\
\hline AMA positive & -4 \\
\hline \multicolumn{2}{|l|}{$\begin{array}{l}\text { Hepatitis viral markers (IgM anti-HAV, HBsAg, IgM } \\
\text { anti-HBc, anti-HCV, HCV-RNA) }\end{array}$} \\
\hline Positive/Negative & $-3 /+3$ \\
\hline \multicolumn{2}{|l|}{$\begin{array}{l}\text { Recent or current use of known or suspected } \\
\text { hepatotoxic drugs }\end{array}$} \\
\hline Yes/No & $-4 /+1$ \\
\hline \multicolumn{2}{|l|}{ Average alcohol intake } \\
\hline$<25$ g/day / >60 g/day & $+2 /-2$ \\
\hline \multicolumn{2}{|l|}{$\begin{array}{l}\text { Other autoimmune disease(s) in patient or first degree } \\
\text { relatives }\end{array}$} \\
\hline Yes/No & $+2 / 0$ \\
\hline \multicolumn{2}{|l|}{$\begin{array}{l}\text { Additional parameters (should be allocated only if } \\
\text { ANA, SMA or LKM-1 are negative) }\end{array}$} \\
\hline $\begin{array}{l}\text { HLA DR3, DR4, or other HLA with published } \\
\text { association with AIH }\end{array}$ & +1 \\
\hline $\begin{array}{l}\text { Seropositivity for any of ANCA, anti-LC1, anti-SLA/ } \\
\text { LP, anti-ASGPR and anti-sulfatide }\end{array}$ & +2 \\
\hline \multicolumn{2}{|l|}{ Liver histology } \\
\hline Interface hepatitis & +3 \\
\hline Predominant lymphoplasmacytic infiltrate & +1 \\
\hline Rosetting of liver cells & +1 \\
\hline None of the above & -5 \\
\hline Biliary changes & -3 \\
\hline Other changes & -3 \\
\hline Response to therapy: Complete/Relapse & $+2 /+3$ \\
\hline
\end{tabular}

Definite AIH if greater than 15 before treatment or greater than 17 post-treatment; probable AIH if between 10-15 before treatment or 12-17 post-treatment

IgG, immunoglobulin G; ANA, antinuclear antibodies; SMA, smooth muscle antibodies; anti-LKM1, anti-liver/kidney microsomal antibody type-1; AMA, antimitochondrial antibodies; HLA, human leukocyte antigens; $A I H$, autoimmune hepatitis; ANCA, anti-neutrophil cytoplasmic antibodies; anti$L C 1$, antibodies against liver cytosol type-1 antigen; anti-SLA/LP, antibodies against soluble liver antigens/liver pancreas; anti-ASGPR, antibodies against the asialoglycoprotein receptor; IgM anti-HAV, hepatitis A virus IgM antibody; $H B s A g$, surface antigen of hepatitis B virus; IgM anti-HBc, IgM antibody against the core antigen of hepatitis B virus; ULN, upper limit of normal

\section{RECOMMENDATIONS 17-19}

- The 2008 simplified score should be used for AIH diagnosis in daily clinical practice, as it is a userfriendly clinical tool (II-2)

- The previously established (1999) revised score can be helpful in diagnosing difficult AIH cases, as it includes response to treatment as an important parameter (II-2)

- Diagnostic scores should not be used for the diagnosis of AIH-PBC and AIH-PSC variants. They may be used with caution for the diagnosis of AIH during childhood and for acute or fulminant disease, as they are not very well validated in these settings (II-2)

diagnosis [18] (Table 5). However, it proved quite complex for everyday use, while it was rather unable to safely distinguish AIH from cholestatic syndromes or AIH variants $[65,104,105]$. In 2008, the IAIHG proposed a simplified score for daily routine clinical practice, which is user-friendly, as it is based on autoantibody detection, IgG, liver histology, and seronegativity for viral hepatitis markers [19] (Table 6). This newer score seems to bear lower sensitivity ( $95 \%$ vs. 100\%) but higher specificity and accuracy compared with the original revised score [106-108]. In general, however, physicians should keep in mind that any score should be used only as an aid to AIH diagnosis [109]. This is true, for example, in acute or fulminant AIH cases, AIH variants, children with $\mathrm{AIH}$ and DILI cases resembling AIH, as diagnosis by using the abovementioned diagnostic scores may be missed in such cases [28,29,68,99,108,110-112]. In particular, because of poor validation of the scores in the pediatric population, different scores have been suggested for child patients [69].

\section{Management}

All AIH patients who have active disease, even those with advanced fibrosis or cirrhosis, should receive immunosuppression in an attempt to achieve complete remission and to prevent the progression of liver disease through either maintenance therapy or a sustained remission following treatment withdrawal $[6-8,10,33,60,98,113]$.

\section{Indications for treatment (Fig. 3)}

Untreated patients with moderate to severe disease (confluent necrosis on biopsy, AST/ALT $>5 \times \mathrm{ULN}$ and IgG $>2 \times \mathrm{ULN}$ ) have a poor prognosis, while immunosuppression can improve symptoms and liver biochemistry, including IgG, leading to prolonged survival $[114,115]$. Spontaneous resolution of AIH may occur and treatment can be withheld. However, because of the fluctuating and unpredictable disease 
Table 6 Simplified criteria for autoimmune hepatitis diagnosis (adapted from [19])

\begin{tabular}{|c|c|c|}
\hline Parameter/Feature & Finding & Points \\
\hline ANA or SMA pos & $\geq 1: 40$ & +1 \\
\hline $\begin{array}{l}\text { ANA or SMA pos } \\
\text { or anti-LKM pos } \\
\text { or anti-SLA/LP pos }\end{array}$ & $\begin{array}{l}\geq 1: 80 \\
\geq 1: 40 \\
\text { Positive }\end{array}$ & $+2 *$ \\
\hline $\begin{array}{l}\text { Liver histology } \\
\text { (presence of hepatitis } \\
\text { is necessary) }\end{array}$ & $\begin{array}{l}\text { Typical AIH** } \\
\text { Compatible with } \mathrm{AIH}^{* *} \\
\text { Atypical** }\end{array}$ & $\begin{array}{c}+2 \\
+1 \\
0\end{array}$ \\
\hline Serum IgG levels & $\begin{array}{l}>\text { Upper normal limit } \\
>1.1 \text { Upper normal limit }\end{array}$ & $\begin{array}{l}+1 \\
+2\end{array}$ \\
\hline $\begin{array}{l}\text { Absence of viral } \\
\text { hepatitis*** }\end{array}$ & $\begin{array}{l}\text { Yes } \\
\text { No }\end{array}$ & $\begin{array}{c}+2 \\
0\end{array}$ \\
\hline \multicolumn{2}{|l|}{ Sum } & $\begin{array}{l}\geq 6: \text { probable AIH } \\
\geq 7 \text { : definite AIH }\end{array}$ \\
\hline \multicolumn{3}{|c|}{$\begin{array}{l}\text { *Addition of points achieved for all autoantibodies (maximum, } 2 \text { points). } \\
\text { **Definition of typical lesions as in section "Liver histology"; Compatible } \\
\text { liver histology: chronic hepatitis with lymphocytic infiltration without all } \\
\text { the features considered typical; Atypical: histological lesions supporting } \\
\text { another diagnosis. ***In chronic cases absence of hepatitis B and C viral } \\
\text { markers; in acute cases absence of serological markers of acute hepatitis A, } \\
\text { B, C, D and E is needed. ANA or SMA detection refers to the use of indirect } \\
\text { immunofluorescence assay, not ELISA }\end{array}$} \\
\hline $\begin{array}{l}\text { ANA, antinuclear antibod } \\
\text { anti-liver/kidney microson } \\
\text { soluble liver antigens/liver } \\
\text { immunoglobulin } G\end{array}$ & $\begin{array}{l}\text { s; SMA, smooth muscle antibo } \\
\text { l antibody; anti-SLA/LP, anti } \\
\text { ancreas; AIH, autoimmune he }\end{array}$ & $\begin{array}{l}\text { dies; anti-LKM, } \\
\text { bodies against } \\
\text { epatitis; IgG, }\end{array}$ \\
\hline
\end{tabular}

behavior, which carries a considerable risk of subclinical disease progression, these patients should be followed over the long term (3-6 monthly) in order not to miss a later clinical and/or biochemical exacerbation [33,116,117].

\section{Induction therapy}

The initial first-line treatment for the induction of disease remission includes prednisolone in an individualized once-daily dose $(0.5-1 \mathrm{mg} / \mathrm{kg} /$ day $)$, followed usually after two weeks by $50 \mathrm{mg} /$ day azathioprine (if bilirubin is $<6 \mathrm{mg} / \mathrm{dL}$ ) because this combination was associated with significantly fewer side-effects compared with prednisolone monotherapy $[7,114,115,118-120]$. The rationale of delaying azathioprine initiation is based firstly on resolving diagnostic uncertainties, as transaminases decrease sharply in AIH cases after prednisolone, and secondly to avoid diagnostic challenges between azathioprine hepatotoxicity and primary non-

\section{STATEMENTS 6-7}

- Definition of biochemical remission: Normalization of IgG, AST and ALT values (II-2)

- Definition of histological remission: Absence or minimal hepatitis (HAI $\leq 4)(\mathrm{II}-2)$

\section{RECOMMENDATIONS 20-22}

- AIH therapy should aim to achieve complete biochemical and histological remission in an attempt to prevent potential disease progression (II-2)

- All patients having active disease, even those with advanced fibrosis or cirrhosis, should be treated (I)

- Treatment can be withheld in patients with spontaneous remission for whom a close long-term follow up is advised in order not to miss an AIH exacerbation (III)

response. Azathioprine is then gradually increased according to the response or its potential toxicity up to $1-2 \mathrm{mg} / \mathrm{kg} /$ day. Azathioprine alone should not be used as induction therapy as it has been associated with high mortality rates [6-10,60,118].

The primary aim should be the achievement of complete clinical and biochemical remission at the lowest corticosteroid dose, or even complete withdrawal using a rapid manner of corticosteroid tapering (Table 7) in order to avoid corticosteroid-dependent disease and development of several significant side-effects. Azathioprine should be used with caution in pregnancy, malignancies, cytopenias and established thiopurine methyltransferase (TPMT) deficiency.

Many patients (15-25\%) develop side-effects or are intolerant to corticosteroid therapy alone, or in combination with azathioprine [121]. In addition, measurement of TPMT activity or genotyping, along with determination azathioprine of metabolite, are time consuming processes and are not widely available, while they neither provide convincing proof of avoidance of toxicity nor predict the treatment response [122-124]. On the other hand, in a review of 11 randomized controlled trials published from 1950-2009, which included 578 AIH patients (363 treatment-naïve), Lamers et al [115] reported a mean $43 \%$ remission rate after prednisolone with or without azathioprine treatment, much lower than those reported in the current literature (approximately 65-80\%) [125], suggesting that this kind of treatment is far from ideal. In parallel, a large multicenter study in The Netherlands showed that AIH relapse is almost ubiquitous after treatment withdrawal, even though the patients were in long-term remission ( $>2$ years), further supporting concerns regarding the conventional treatment's lack of long-term efficacy [126].

Because of these concerns, mycophenolate mofetil (MMF) in combination with prednisolone, or budesonide in combination with azathioprine have been used as first-line induction treatment [13,34,127-134]. MMF blocks purine synthesis, inhibits DNA synthesis and has a selective antiproliferative effect on B- and T-cells. MMF has a 5-fold potent inhibitory effect on the typeII isoform of inosine-5'-monophosphate dehydrogenase, which depletes guanosine nucleotide specifically in activated T- and B-cells without affecting the type-I isoform and thus results in more powerful and selective immunosuppression with few sideeffects [135]. In addition, in patients and experimental animal models, it has been shown that MMF-based immunosuppression 


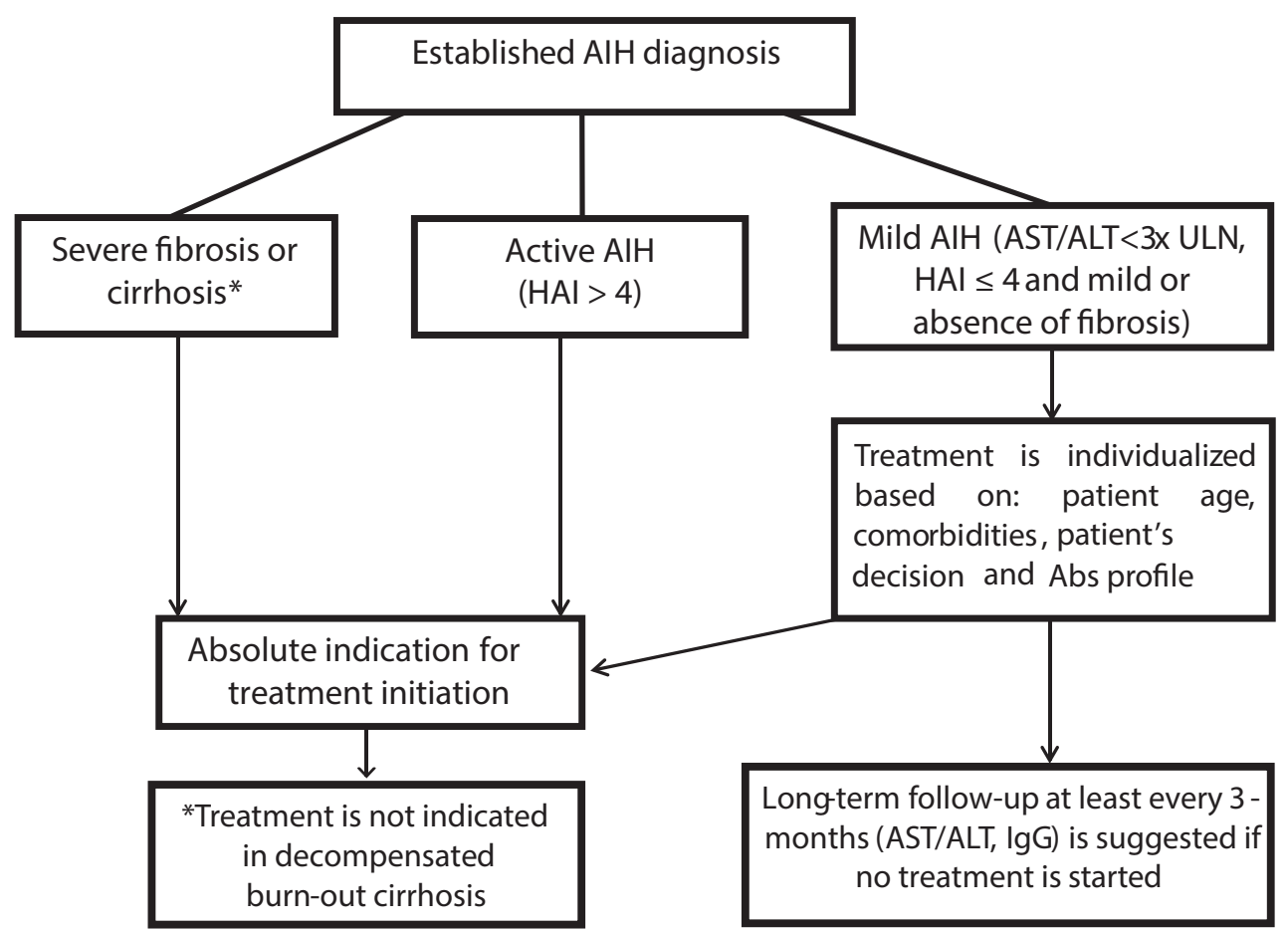

Figure 3 Indications for treatment initiation in defined cases of autoimmune hepatitis (AIH)

ULN, upper limit of normal; Abs, autoantibodies; HAI, histological activity index; AST, aspartate aminotransferase; ALT, alanine aminotransferase; IgG, immunoglobulin $G$

Table 7 Suggested treatment schedule for adults with recent diagnosis of autoimmune hepatitis (e.g., $70 \mathrm{~kg}$; adapted from $[60,115]$ )

\begin{tabular}{lcc}
\hline Week & Prednisolone $(\mathrm{mg} /$ day $)$ & Azathioprine (mg/day) \\
\hline 1 & $70(=1 \mathrm{mg} / \mathrm{kg})$ & - \\
2 & 60 & - \\
3 & 50 & 50 \\
4 & 40 & $100^{* *}$ \\
5 & 30 & 100 \\
6 & 25 & 100 \\
7 & 20 & 100 \\
$8+9$ & 15 & 100 \\
$10+11$ & 12.5 & 100 \\
\hline From 12 & $10^{*}$ & 0 .
\end{tabular}

A lower prednisolone dose can be used initially in mild disease or in early relapses during corticosteroids withdrawal (e.g., $0.5-0.7 \mathrm{mg} / \mathrm{kg} /$ day). The tapering schedule of corticosteroids should be individualized according to the rapidity of the response and the development of side-effects. ${ }^{*}$ If transaminases are normalized, prednisolone could be reduced to $7.5 \mathrm{mg} /$ day and after 3 months to $5 \mathrm{mg} /$ day, aiming at complete withdrawal after 6-8 months (or after 3-4 months at $2.5 \mathrm{mg} /$ day) according to a personalized assessment of the patient's risk and response. ${ }^{*}$ Azathioprine dose according to body weight $(1-2 \mathrm{mg} / \mathrm{kg})$

could restore the regulatory T-cells [136-138], considered very important in AIH pathogenesis [139-141].

In this context, two uncontrolled real-world prospective studies from Greece $[34,128]$, including the largest numbers of treatment-naïve AIH patients ever published $(n=59$ and $\mathrm{n}=109$ ), showed that MMF at a dose of 1.5-2 g/day in two divided doses was safe (discontinuation in 3\%) and effective as first-line treatment to induce and maintain response with a rapid steroid sparing effect (Fig. 4). In fact, initial complete response was achieved in $88 \%$ [34] and 93.6\% [128] in a median time of less than 3 months (significantly shorter compared with conventional azathioprine schedules $[23,142]$ ), while on treatment complete remission was achieved in 59.3\% [34] and $71.6 \%$ [128] of patients, compared with the $26 \%$ reported by Muratori et al $[23,143]$ and $43 \%$ by Lamers et al [115]. Most importantly, a recent study by Zachou et al showed the highest rates of remission maintenance off treatment (72-75\%) ever published, for at least a median of 30 months, accompanied by significant improvement in necroinflammatory activity and stable and/or improved fibrosis at second liver biopsy [128,129]. Similar findings independent of the presence of cirrhosis were reported in another retrospective study (84\% response rate) in $29 \mathrm{AIH}$ patients [127].

Budesonide has also been used effectively in a randomized study (9 mg/day) in combination with azathioprine in noncirrhotic AIH patients [130]. Biochemical remission (IgG normalization was not included in the response criteria) without the typical steroid-induced side-effects was found more frequently in budesonide-treated patients compared with the prednisone-treated group ( $47 \%$ vs. $18 \%$ ), and side-effects were fewer ( $28 \%$ vs. 53\%) [130]. However, response rates and side-effects in the control arm were surprisingly lower and higher, respectively, than in earlier studies, presumably because of the initial fixed-dose and fixed-dose reduction schedule in the prednisone group, whereas in the budesonide group the drug was given at a high dose until a response was 
Start with $1 \mathrm{~g} /$ day MMF following by gradual increase (500 $\mathrm{mg} /$ week) up to a final dose of $2 \mathrm{~g} /$ day +

Prednisolone $0.5-1 \mathrm{mg} / \mathrm{kg} /$ day

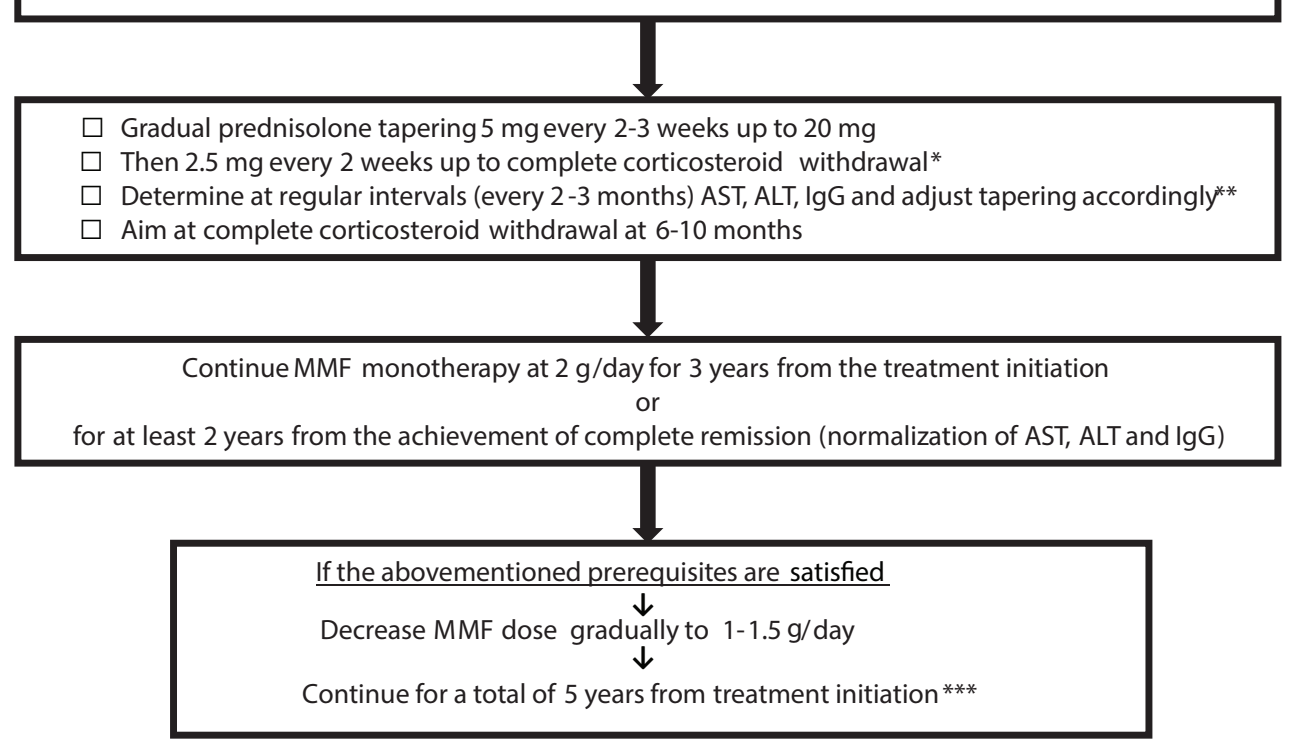

Figure 4 Suggested therapeutic algorithm for prednisolone in combination with mycophenolate mofetil (MMF) in treatment-naïve AIH patients. *In patients with risk factors (e.g., anti-LKM, anti-LC1, anti- $\alpha$-actinin, anti-SLA/LP, cirrhosis at diagnosis) the tapering schedule could be applied every 3 weeks. ${ }^{*}$ In relapses ( $\uparrow$ AST, ALT $\pm \operatorname{IgG}$ ) prednisolone should be increased to the dose of initial complete response and then tapered, either by increasing the time interval twofold or by decreasing the dose of prednisolone tapering by half at the same time. ***In relapses after corticosteroid withdrawal restart prednisolone at the dose of initial complete response and taper according to **. MMF is given in two divided doses

AIH, autoimmune hepatitis; anti-LKM, anti-liver/kidney microsomal antibody; anti-LC1, antibodies against liver cytosol type-1 antigen; anti-SLA/ $L P$, antibodies against soluble liver antigens/liver pancreas; AST, aspartate aminotransferase; ALT, alanine aminotransferase; IgG, immunoglobulin $G$

achieved, thus suggesting a therapeutic bias. In addition, data on the histologic response in budesonide-treated patients are still lacking, whereas other small studies or case reports have shown either failure or exacerbation of AIH during budesonide monotherapy, making the advantages of a more expensive regimen as first-line therapy in AIH uncertain [144-146].

\section{Maintenance therapy}

Patients with mild necroinflammatory activity at initial biopsy, intolerant to azathioprine and have achieved complete biochemical response, can receive prednisolone monotherapy at the lowest dose that can maintain remission. In all other patients, the aim should be prednisolone off

\section{STATEMENTS 8-9}

- The long-term efficacy of the conventional treatment is uncertain, as $15-25 \%$ of patients develop intolerance or side-effects (II-2)

- Long-term biochemical and histological data on budesonide safety and efficacy are lacking (I)

\section{RECOMMENDATIONS 23-27}

- Induction treatment for AIH should be individualized and response-guided (II-2)

- Prednisolone at one oral dose of $0.5-1 \mathrm{mg} / \mathrm{kg} / \mathrm{day}$ in the morning, combined with azathioprine at an initial morning dose of $50 \mathrm{mg} /$ day usually after 2 weeks, if bilirubin is $<6 \mathrm{mg} / \mathrm{dl}$, should be the firstline therapy for AIH (I)

- Azathioprine should then be increased up to 1-2 mg/ $\mathrm{kg} /$ day (maintenance dose) (II-2)

- In specialized AIH centers, prednisolone (0.5-1 mg/kg/day), combined with MMF (2 g/ day) from the beginning of treatment if bilirubin is $<6 \mathrm{mg} / \mathrm{dL}$, may be used as first-line therapy, since real-world studies showed high rates of remission maintenance off treatment accompanied by improved liver histology (II-3)

- In non-cirrhotic AIH patients, budesonide (9 $\mathrm{mg} /$ day) in combination with azathioprine may be used as induction treatment in those with serious comorbidities that might be exacerbated by conventional corticosteroid therapy (II-2) 
monotherapy with individualized adjusted azathioprine ( $2 \mathrm{mg} / \mathrm{kg} /$ day), or alternatively MMF doses (1.5-2 g/day) $[7,34,115,119,147]$. The total duration of immunosuppression should be at least 3 years, with at least the last 2 years having persistent complete biochemical response (normalization of transaminases and $\operatorname{IgG}$ ). In patients who have received adequate induction and maintenance immunosuppression, but who have not achieved biochemical or histological remission, immunosuppression should not be stopped, as relapse will occur almost universally.

\section{Relapse of the disease}

Relapse of $\mathrm{AIH}$ is defined as the reappearance of clinical or laboratory markers of active disease (ALT $\geq 2-3 \times \mathrm{ULN}$ and/ or an increase in $\operatorname{IgG}$, usually preceded by ALT elevation) [60] after achievement of complete remission during the induction therapy, or during maintenance therapy and/or after complete discontinuation of treatment. In this setting, liver biopsy is usually not recommended. Relapses are particularly frequent

\section{RECOMMENDATIONS 28-32}

- The optimal maintenance treatment should be corticosteroid-free monotherapy with azathioprine, or alternatively MMF (II-2)

- Low-dose long-term prednisolone monotherapy may be used to maintain remission only in patients with mild disease and azathioprine intolerance who have achieved complete response after induction therapy (II-2)

- Maintenance therapy should be adjusted to a dosage that can maintain persistent biochemical response (normalization of AST, ALT and IgG) (II-2)

- Immunosuppression should be given for a total of at least 3 years, and for at least 2 years after the achievement of complete biochemical response (II-2)

- Maintenance therapy should not be withdrawn without a complete biochemical or histological response (HAI>3) (II-2)

with conventional treatment schedules and usually occur 6-12 months after therapy cessation, although a relapse episode may even present many years later $[126,148,149]$. Remission maintenance is usually associated with a rapid response to previous immunosuppression, with steadily normal transaminases and/or IgG, higher baseline transaminases, no residual necroinflammatory activity on liver histology before treatment withdrawal and longer treatment duration ( $\geq 4$ years) [7,34,128,150-152].

Treatment of relapses is similar to the initial treatment and is also effective in re-inducing a full response. AIH patients who suffer from multiple relapses develop more side-effects and are likely to have worse outcomes $[149,153,154]$.

\section{Primary treatment endpoints and discontinuation of therapy}

The ideal treatment endpoints are a complete clinical,

\section{RECOMMENDATIONS 33-36}

- Patients with AIH should remain under close longterm monitoring after treatment discontinuation, as relapses may occur most commonly in first 6-12 months but even many years later (II-2)

- IgG elevation usually precedes transaminase increase in patients with AIH relapse, but liver biopsy is not recommended (II-2)

- Treatment of relapses should be similar to the initial treatment schedule; it is also effective in re-inducing full remission (II-2)

- Long-term, probably permanent, maintenancetreatment should be recommended in AIH patients who have been treated adequately ( $\geq 4$ years of immunosuppression) but relapse during drug-withdrawal or maintenance treatment (II-2)

biochemical and histological response with prolonged off treatment remission $[7,60,118,143,150,152,153]$. In real-life, however, these endpoints are achieved in a minority of patients who discontinue therapy based on prednisolone alone or in combination with azathioprine [115,143], while data on the same issue in budesonide-treated patients are still lacking. In contrast, real-word studies showed high rates of maintained offtreatment remission accompanied by histological improvement in patients treated with prednisolone in combination with MMF as first-line therapy [34,128,129].

Treatment withdrawal can be suggested only in those patients who have achieved continuous complete biochemical remission for at least the last 2 years of treatment, and especially in those with ALT below half the ULN along with IgG $<1200 \mathrm{mg} / \mathrm{dL}$ [155]. In these patients, liver biopsy before treatment withdrawal is advisable [156]. However, complete treatment withdrawal is almost impossible in difficult-to-treat patients (see below), including cirrhotics and patients with AIH-2.

\section{Follow-up before and during treatment}

Patients under conventional or budesonide/azathioprine schedules should be followed with baseline and weekly tests for transaminases, albumin, prothrombin time, fasting glucose and full blood count during the first month. In patients 


\section{STATEMENT 10}

- Only a very small proportion of patients stay in remission without maintenance therapy with the conventional treatment regimens (II-2)

\section{RECOMMENDATIONS 37-38}

- In AIH patients who have been in persistent complete biochemical remission for at least the last 2 years of immunosuppression, a liver biopsy should be recommended before treatment discontinuation (II-2)

- The decision about treatment withdrawal should be based on direct collaboration between patients and doctors (II-2)

under prednisolone/MMF, the above data could be obtained at 2-3-month intervals, along with IgG determination. After corticosteroid tapering, monitoring intervals can be every 3 months and every 3-6 months during maintenance therapy.

Baseline hepatitis B (HBV) and A serology is recommended before treatment, along with the respective vaccination for those not indicating previous vaccination or virus exposure. For HBV surface antigen-positive (HBsAg) patients, preemptive therapy with either entecavir or tenofovir is strongly recommended according to the EASL and the Hellenic Center for Disease Control and Prevention (HCDCP) CPG [157,158]. Vaccination against Streptococcus pneumoniae, along with yearly influenza vaccination, should also be given to all patients.

Dual energy X-ray absorptiometry scanning assessment before treatment initiation and at 1-5-years intervals seems rational, but there are no specific data to support this assertion. Likewise, though no specific data exist concerning the use of calcium and vitamin D in patients under immunosuppression, such treatment seems reasonable, as in other diseases under corticosteroids.

\section{Specific conditions and difficult-to-treat patients}

\section{Non-responders}

Non-response includes a partial or incomplete response and treatment failure (null response), associated or not with an acute/severe form of the disease.

\section{Partial response}

A partial response means that there is some improvement in clinical, biochemical and histological parameters but without

\section{RECOMMENDATIONS 39-40}

- Vaccination against hepatitis A, HBV, pneumococcus (particularly in cirrhotics) along with yearly influenza vaccination should be administered to all AIH patients (III)

- Bone density determination is recommended at treatment initiation, along with vitamin D supplementation and adequate calcium intake in all patients receiving corticosteroids (II-2)

reaching complete remission despite treatment adherence. These patients have abnormal transaminases (usually below 2-3×ULN) or necroinflammatory activity on histology $[6,7,10,60]$.

In partial responders under conventional treatment, an option is to increase azathioprine to $2 \mathrm{mg} / \mathrm{kg} / \mathrm{day}$ in combination with prednisolone $(5-10 \mathrm{mg} / \mathrm{kg} /$ day $)$, followed by a repeat liver biopsy after $12-24$ months $[6,9,10,60]$. In patients with a partial response after adequate treatment with budesonide-based schedules, a change to prednisolone (>20 mg/day initially) could be considered [146]. If complete biochemical and histological remission is not achieved, the aim should be either the lowest achievable biochemical activity in parallel with minimum side-effects, or the administration of alternative second-line therapeutic agents [159].

\section{Treatment failure}

Primary complete biochemical remission after adequate treatment initiation is the rule $(90-95 \%$ of patients); therefore, reassessment of diagnosis and treatment adherence should be considered in non-responders. Non-response is not well-defined, but usually the absence of a transaminase decline of at least $25 \%$ from baseline after 2-3 weeks should be considered as non-response. It is also important to remember that other conditions may develop concurrently during the AIH course, such as viral infections or DILI, which if unrecognized, could be mistakenly regarded as a null response or flares [71,72,160,161].

Treatment failure can be seen either in patients with an acute/severe or even fulminant disease form, or in those without such intense severity. Data on patients with acute/ severe presentation are scarce, consisting mostly of real-life non-randomized studies with a small number of patients and varying, mostly arbitrary entry criteria, because the precise definition of this form of AIH is still missing [112,162-171]. Therefore, the role and timing of corticosteroids in modifying the outcome of acute/severe $\mathrm{AIH}$ remains unclear, as it is ambiguous whether such patients should be given a corticosteroids trial, a priority listing for liver transplantation, or both. Potts and Verma recently reviewed five retrospective studies, each with a small number of patients, including in total 85 patients with AIH-related acute liver failure [170]. Sixty- 
nine patients (89.2\%) received immunosuppression, mostly oral corticosteroids, and had remission rates of $8.3-50 \%$, while $43.5 \%$ underwent or were listed for liver transplantation and $33 \%$ died. The largest recent studies in acute/severe AIH come from France $(n=104)$ and Greece $(n=42)$ [112,171]. In the multicenter retrospective French study, an overall survival rate of $90 \%$ was reported (median follow up: 2.3 years), although early liver transplantation was required in one third of patients. The beneficial effect of corticosteroids was observed in $66 \%$ of patients, mainly in those with low international normalized ratio (INR) at baseline and improvement in liver function during the first week of treatment [171]. In the Greek study, high-dose intravenous corticosteroids were given (prednisolone $1.5 \mathrm{mg} / \mathrm{kg} /$ day) in the early stages of acute/ severe $\mathrm{AIH}$, defined as an acute presentation without any sign of hepatic encephalopathy and transaminases $>10 \times$ ULN, INR $\geq 1.5$ and bilirubin $\geq 4 \mathrm{mg} / \mathrm{dL}$ at any time during the acute course [112]. This management appeared to prevent disease deterioration without increasing morbidity and mortality (long-term overall survival without transplantation: 95.2\%; median follow up: 5.3 years).

Conclusively, despite the low level of evidence, the available data indicate that all patients with acute/severe AIH should be considered for a corticosteroid trial at the earliest opportunity (the sooner the better), using high doses of prednisolone (>1 mg/kg/day) intravenously [172]. Failure to improve within 7 days should lead to emergency listing for liver transplantation [167]. The prophylactic use of antibiotics/antifungals is not supported by the most recent studies [112,171], but they should be kept in mind and may be justified at an individualized basis.

The other form of treatment failure without intense severity is characterized by minimal, or even no improvement in the clinical and biochemical parameters after several weeks of standard regimen, despite confirmation of diagnosis and treatment adherence. In these patients, determination of active azathioprine metabolites, such as thioguanine nucleotides (TGN), could be helpful in revealing a lack of adherence to treatment or an altered azathioprine metabolism, although the therapeutic range of TGN levels is not precisely known in AIH [173]. As endorsed by EASL, AASLD and the British Society of Gastroenterology GPG [6,10,60], an increase of prednisolone for at least one month and azathioprine to the maximum doses $(1 \mathrm{mg} / \mathrm{kg} /$ day and $2 \mathrm{mg} / \mathrm{kg} /$ day, respectively) seems rational. However, despite this intense treatment strategy, most patients may not respond, while they carry increased risks for drug-related side-effects. Therefore, management by expert centers should be suggested as soon as possible for these patients.

\section{STATEMENT 11}

- Definition of the acute/severe form of AIH is an urgent unmet need (I)

\section{RECOMMENDATIONS 41-47}

- In partial responders under a conventional regimen, an increase of the azathioprine dose to $2 \mathrm{mg} / \mathrm{kg} /$ day in combination with $5-10 \mathrm{mg} / \mathrm{kg} /$ day prednisolone is recommended (II-3)

- In partial responders under a budesonide-based regimen, a change to prednisolone ( $>20 \mathrm{mg} /$ day) could be considered (III)

- In partial responders not able to achieve complete remission despite the above options, the goal should be the lowest achievable biochemical activity with a minimum of side-effects, or administration of alternative second-line therapeutic agents after consultation at a specialized center (II-3)

- Failure of primary complete biochemical remission after adequate treatment should raise strong suspicion of misdiagnosis or non-compliance with therapy (II-2)

- All AIH patients presenting with the acute/severe form of the disease should be considered for a high-dose corticosteroid trial ( $>1 \mathrm{mg} / \mathrm{kg} /$ day) at the earliest opportunity (the sooner the better), and preferably intravenously, but failure to improve within 7 days should lead to emergency listing for liver transplantation (II-3)

- In non-responders without intense severity, prednisolone and azathioprine at the maximum dosage $(1 \mathrm{mg} / \mathrm{kg} / \mathrm{day}$ and $2 \mathrm{mg} / \mathrm{kg} /$ day, respectively) could be tried, followed by management at expert centers in the case of nonresponse (II-2)

- Determination of TGN levels could help the redesign of treatment strategy, as undetectable TGN may indicate altered azathioprine metabolism or non-compliance, while high TGN levels may suggest toxicity (II-2)

\section{Non-adherence}

Non-adherence to treatment is an important problem during long-term follow up, particularly among children and adolescents under corticosteroids, resulting in frequent relapses or flares of AIH $[174,175]$. The management of non-compliance is difficult; therefore, a multidisciplinary approach is needed, including psychologists, social and youth workers, health carers, committed nurses, and pediatric and adult hepatologists in an attempt to re-motivate the young patient [176].

In addition, high rates of depression and anxiety have recently been reported in AIH patients [27] Thus, considerable attention is needed for those not appropriately followed for the psychiatry compartment, because this behavior could cause an increased frequency of non-adherence, leading to these patients erroneously being considered as non-responders and candidates for alternative therapies, with unexpected consequences [177]. 


\section{RECOMMENDATIONS 48-50}

- Treatment adherence should be of outmost importance for all patients and especially for children, adolescents and young adults (II-2)

- The transition from childhood to adult care should be based on a multidisciplinary approach by special transition services (II-3)

- Considerable attention should be given to patients with anxiety or depression in order to be sure that the psychiatric follow up and treatment are appropriate before appraising these patients as non-responders to AIH therapy (III)

\section{Intolerance to and side-effects of treatment}

Corticosteroid side-effects are numerous and develop in up to $80 \%$ of patients receiving steroid monotherapy for more than 2 years, mainly at doses $>15 \mathrm{mg} /$ day. However, corticosteroid discontinuation because of severe adverse events is observed in $15 \%$. Combination with azathioprine is associated with a much lower rate of side-effects [112,147]. In non-cirrhotic prednisolone responders who nevertheless develop sideeffects, even though azathioprine has been increased to the highest dose, a switch to budesonide could be suggested.

Azathioprine side-effects occur in about $25 \%$ of AIH patients, accompanied by drug withdrawal in approximately $10-15 \%$. In patients intolerant to or with side-effects from azathioprine (bone marrow suppression, nausea, vomiting, pancreatitis, etc.), a switch to MMF ( $2 \mathrm{~g}$ /day) with subsequent prednisolone tapering appears to be an excellent alternative [178-186]. Other alternatives are steroid monotherapy in patients with mild disease, budesonide, mercaptopurine or thioguanine, tacrolimus, ciclosporin, methotrexate, cyclophosphamide, allopurinol, and biologic regimens, including tumor necrosis factor $\alpha$ (TNFa) blockade agents and rituximab [187-194].

\section{RECOMMENDATIONS 51-54}

- In patients intolerant to azathioprine, MMF should be the second-line treatment (II-2)

- Mercaptopurine or thioguanine could also be an alternative option (III)

- If adequate conventional treatment with azathioprine cannot maintain remission in corticosteroid responders who nevertheless have severe steroid side-effects, switching to budesonide may be considered (II-3)

- Inpartialornon-respondersafteradequate conventional treatment, alternative therapies with ciclosporin or tacrolimus, methotrexate, cyclophosphamide, rituximab or TNFa blockade agents may be initiated only at specialized centers, although their effectiveness has not been investigated in proper clinical trials (II-3)

\section{Non liver-related comorbidities and aging}

Approximately one third of older AIH patients ( $>65$ years) already have cirrhosis or advanced fibrosis at diagnosis, although they are more frequently asymptomatic at presentation compared to younger patients $[25,27,33,195]$. These patients achieve biochemical response more frequently and have a higher prevalence of concurrent autoimmune diseases compared with younger patients $[25,196,197]$.

In asymptomatic elderly patients with mild disease, the decision about treatment initiation could be based on the presence and the severity of other comorbidities, such as uncontrolled diabetes mellitus, refractory arterial hypertension, established osteoporosis or a previous or current history of psychosis. In this context, it is better to choose a watch-andwait strategy, but close follow up of these patients is strongly advised. Although there is no convincing data concerning the management of elderly AIH patients with mild disease and no severe comorbidities $[33,116,197]$, it seems rational to initiate immunosuppression using a lower starting prednisolone dose $(0.5 \mathrm{mg} / \mathrm{kg} /$ day $)$, followed by a more rapid steroid de-escalation schedule in combination with azathioprine (1-2 mg/kg/day). Another attractive option for these patients without cirrhosis may be the use of budesonide ( $9 \mathrm{mg} /$ day) plus azathioprine.

In elderly patients with at least moderate necroinflammatory activity, treatment is recommended, but again the choice of steroid therapy and the tapering schedule should be considered carefully. The same is true for all AIH patients, irrespective of age, who have concurrent severe comorbidities.

\section{RECOMMENDATIONS 55-56}

- Treatment is recommended in elderly patients with at least moderate necroinflammatory activity. In the presence of other comorbidities, the type of steroid therapy and the tapering schedule should be considered carefully in all ages (II-3)

- In asymptomatic elderly patients with mild interface activity and comorbidities it is better to watch and wait, but close long-term follow up is strongly advised (II-3)

\section{AlH variants}

Although controlled trials are lacking, the recentEASL CPG for PBChave recommended adding immunosuppression to UDCA in previously well-established $\mathrm{PBC}$ cases if at least moderate interface hepatitis is present on liver biopsy [62,198-200]. Notably, these patients appear to respond to lower immunosuppression dosages and maintain remission after treatment withdrawal at higher rates than patients with AIH alone $[198,199]$. It is uncertain whether AIH patients who develop PBC features will benefit from UDCA administration, but this addition seems logical under reallife conditions, particularly in young patients, because of the potential long-term benefit of UDCA, which may subsequently 
protect the patients from the development of ductopenia and biliary cirrhosis during their lifetime.

Considering the AIH-PSC variant, again there are no controlled trials concerning its management. A combination treatment consisting of immunosuppression and UDCA has been suggested and response criteria have recently been published for autoimmune sclerosing cholangitis, the pediatric form of the variant [69].

However, although biochemical and histological parameters may improve, the biliary tract lesions may progress and therefore the outcome of these patients seems worse compared to those with only AIH $[63,64]$. The combination of UDCA and immunosuppression has also been proposed by EASL CPG for the adults with AIH-PSC variant [201], although the available but inadequate studies show that the long-term prognosis appears worse than for either $\mathrm{AIH}$ cases without PSC characteristics or PSC alone [66,202,203].

\section{RECOMMENDATIONS 57-58}

- In patients with the AIH-PBC variant, a combination of immunosuppression with UDCA is recommended; alternatively, if AIH is the dominant compartment, immunosuppression only should be started and UDCA could be added if remission is not achieved (III)

- In patients with the AIH-PSC variant, the addition of UDCA to immunosuppressive treatment can be considered (III)

\section{Management of AlH in pregnancy}

Large series of pregnant AIH patients from the United Kingdom [37], Germany [204] and Sweden [205] have shown that the new or continued administration of azathioprine had no significant impact on the rate of live birth, termination or miscarriage, or on the gestational period. Interestingly, some unexplained adverse outcomes were found to be associated with anti-SLA/LP and anti-Ro52 detection [204], while a higher Cesarean section rate was recorded in Sweden [205], but again without higher stillbirth or fetal malformation rates compared to controls. Taken together, these findings suggest that the continuation of azathioprine in females with wellestablished AIH after conception appears rational and justified.

As discussed previously, AIH may also present for the first time during pregnancy or more frequently after delivery [37-39]. These cases should be treated as discussed previously for non-pregnant patients. However, as the disease during pregnancy usually has lower activity, a minimal adjustment of immunosuppression (5-10 $\mathrm{mg}$ /day prednisolone $\pm 50-75 \mathrm{mg}$ /day azathioprine) in previously diagnosed patients receiving treatment seems rational. Immunosuppressive treatment should then be increased after delivery to the previous dosages, in order to minimize the risk of flare during post-partum. Complications seem to be more frequent for those patients who have not achieved complete biochemical remission at least one year before conception, while cirrhotic patients carry a high risk of adverse outcomes. Although data regarding breastfeeding in $\mathrm{AIH}$ females under azathioprine are limited, the drug is considered safe, despite the fact that small amounts of its metabolite can be detected in breast milk [206].

\section{RECOMMENDATIONS 59-62}

- Females with $\mathrm{AIH}$ in remission should be advised that they have no contraindication for pregnancy or breastfeeding (II-2)

- Maintenance treatment with prednisolone with or without azathioprine should be continued in previously diagnosed females under therapy (II-2)

- Mild flares can be observed during the first trimester and more frequently especially in the post-partum period, requiring an increase in immunosuppression (II-2)

- MMF should be stopped at least 3 months prior to conception (either in females or males under treatment), as this drug is absolutely contraindicated in pregnancy (II-2)

\section{Management of AlH after liver transplantation}

Recurrence of AIH has been reported in 20-25\% of patients [207] and is usually managed with the standard prednisolone treatment schedules in combination with azathioprine or MMF [208]. Non-responders in this setting could be aided by the use of sirolimus [209]. De novo AIH has been described in approximately $5 \%$ of subjects transplanted for reasons unrelated to $\mathrm{AIH}[53,207]$ and its management is identical to that suggested for recurrent AIH [210].

\section{RECOMMENDATION 63}

- AIH after liver transplantation, either recurrent or de novo, should be managed by the basic treatment principles of AIH (II-3)

\section{Liver-related comorbidities}

In countries with a moderate to high prevalence of $\mathrm{HBV}$ or HCV infections, the coexistence of $\mathrm{AIH}$ with chronic viral hepatitis is not impossible [211-213]. On the other hand, AIH patients can contract viral hepatitis. In these cases, AIH may be overlooked, as the absence of viral hepatitis markers is one of the 4 essential parameters of the simplified criteria for AIH diagnosis [19]. AIH in this situation seems to be more aggressive and carries a poorer prognosis compared to chronic viral hepatitis alone, as AIH could remain untreated in the long term because of its underdiagnosis/misdiagnosis [212]. In patients with chronic $\mathrm{HBV}$ infection and characteristics of AIH at diagnosis, HBV should be treated first according to the EASL and HCDCP CPG 
$[157,158]$ and the need for AIH treatment should be reevaluated after viral suppression. Alternatively, in cases with moderate to severe necroinflammatory activity, immunosuppressive and antiviral treatment could be initiated in parallel. Likewise, in HCV patients with AIH features, DAAs without IFNa should be used first and initiation of immunosuppression could be started after HCV eradication if necroinflammatory activity persists.

Development of $\mathrm{AIH}$ has rarely been reported in human immunodeficiency virus (HIV) infection after the administration of highly active antiretroviral therapy [214,215]. Standard immunosuppression seems safe and effective in inducing remission, without significant complications or development of opportunistic infections [215]. However, as life-threatening infections can indeed be observed, treatment of AIH in this setting should be individualized.

Non-alcoholic fatty liver disease (NAFLD) has become the most common chronic liver disease in the western world (prevalence: 20-30\%). Non-alcoholic steatohepatitis (NASH), with steatosis, hepatocyte ballooning and lobular inflammation, affects $3-5 \%$ of the population and can progress to severe liver fibrosis and cirrhosis [216,217]. The prevalence of NAFLD/ $\mathrm{NASH}$ and its impact on treatment outcome and response in confirmed AIH patients are largely unknown. Obesity worsens the course and treatment response of other autoimmune diseases, such as rheumatoid arthritis, systemic lupus erythematosus, inflammatory bowel disease and psoriasis [218], and preexisting NAFLD seems to potentiate the severity of AIH in the CYP2D6 mouse model [219]. So far, there is only one small retrospective study indicating that patients with concurrent $\mathrm{AIH}$ and NASH (but not simple steatosis) are more likely to present with advanced disease associated with adverse clinical outcomes and decreased survival [220]. Therefore, NAFLD/ $\mathrm{NASH}$ in this setting should be treated strictly and intensely according to current recommendations [216,217], while efforts should be made to use the lowest effective dose of steroids [221].

\section{RECOMMENDATIONS 64-67}

- In AIH patients with concurrent chronic HBV or $\mathrm{HCV}$ at diagnosis, the viral infections should be treated first and AIH therapy could be offered after HBV suppression or HCV eradication if the necroinflammatory activity persists (III)

- In AIH patients who contracted HBV or HCV infections during the AIH course, antiviral treatment with entecavir/ tenofovir or DAAs, respectively, is recommended without stopping immunosuppression (III)

- In HIV patients with AIH, treatment should be given on an individualized basis, as standard immunosuppression seems to be safe and effective but carries a risk of life threatening infections (III)

- In AIH patients with NAFLD/NASH, efforts should be made to ensure strict adherence to NAFLD/NASH guidelines and the use of the lowest effective dose of steroids for AIH, although the impact of NAFLD/NASH on treatment outcome and response in $\mathrm{AIH}$ is unknown (III)

\section{Concluding remarks}

AIH is characterized by genetic, clinical, laboratory, histological and serological heterogeneity and therefore, it might be underestimated or unrecognized. Its diagnosis is based on the presence of polyclonal hypergammaglobulinemia, circulating autoantibodies, interface hepatitis on liver histology, absence of viral hepatitis and a favorable response to immunosuppression. In particular, autoantibodies detection and the interpretation of histological findings are considered the hallmark for a timely diagnosis. Most of the affected patients are treated very efficiently with at least near normal life expectancy and quite good quality of life. However, many patients still have experience of remarkable morbidity because of delayed or missed diagnosis, drugs intolerance and sideeffects, partial treatment response or flares, poor management and poor adherence. The establishment of major centers bearing special expertise on this disease diagnosis and control will be a governing factor in improving management of patients. Also, research on AIH etiology and its underlying pathogenetic mechanisms will be the clue to improve therapy of AIH. So far, most patients need long-life immunosuppressive treatment but patients want cure, not only remission of the disease. In an attempt to achieve curative treatment, we have to work hard together with basic scientists and follow developments in immunology and autoimmunity.

\section{References}

1. Waldenström J. Leber. Blutproteine und Nahrungseiweiss. Deutsch Z Verdau Stoffwechselkr 1950;15:113-119.

2. Cowling DC, Mackay IR, Taft LI. Lupoid hepatitis. Lancet 1956;268:1323-1326.

3. Mackay IR, Weiden S, Hasker J. Autoimmune hepatitis. Ann NY Acad Sci 1965;124:767-780.

4. Johnson PJ, McFarlane IG. Meeting report: International Autoimmune Hepatitis Group. Hepatology 1993;18:998-1005.

5. Shaneyfelt TM, Mayo-Smith MF, Rothwangl J. Are guidelines following guidelines? The methodological quality of clinical practice guidelines in the peer-reviewed medical literature. JAMA 1999;281:1900-1905.

6. Manns MP, Czaja AJ, Gorham JD, et al; American Association for the Study of Liver Diseases. Diagnosis and management of autoimmune hepatitis. Hepatology 2010;51:2193-2213.

7. Zachou K, Muratori P, Koukoulis GK, et al. Review article: autoimmune hepatitis - current management and challenges. Aliment Pharmacol Ther 2013;38:887-913.

8. Gatselis NK, Zachou K, Koukoulis GK, Dalekos GN. Autoimmune hepatitis, one disease with many faces: etiopathogenetic, clinicolaboratory and histological characteristics. World J Gastroenterol 2015;21:60-83.

9. Gleeson D, Heneghan MA; British Society of Gastroenterology. British Society of Gastroenterology (BSG) guidelines for management of autoimmune hepatitis. Gut 2011;60:1611-1629.

10. Mieli-Vergani G, Vergani D, Czaja AJ, et al. Autoimmune hepatitis. Nat Rev Dis Primers 2018;4:18017.

11. Werner M, Prytz H, Ohlsson B, et al. Epidemiology and the initial presentation of autoimmune hepatitis in Sweden: a nationwide study. Scand J Gastroenterol 2008;43:1232-1240.

12. Ngu JH, Bechly K, Chapman BA, et al. Population-based 
epidemiology study of autoimmune hepatitis: a disease of older women? J Gastroenterol Hepatol 2010;25:1681-1686.

13. Delgado JS, Vodonos A, Malnick S, et al. Autoimmune hepatitis in southern Israel: a 15-year multicenter study. J Dig Dis 2013;14:611618.

14. van Gerven NM, Verwer BJ, Witte BI, et al; Dutch Autoimmune hepatitis STUDY group. Epidemiology and clinical characteristics of autoimmune hepatitis in the Netherlands. Scand J Gastroenterol 2014;49:1245-1254.

15. Grønbæk L, Vilstrup H, Jepsen P. Autoimmune hepatitis in Denmark: incidence, prevalence, prognosis, and causes of death. A nationwide registry-based cohort study. J Hepatol 2014;60:612617.

16. Wong RJ, Gish R, Frederick T, Bzowej N, Frenette C. The impact of race/ethnicity on the clinical epidemiology of autoimmune hepatitis. J Clin Gastroenterol 2012;46:155-161.

17. Czaja AJ. Autoimmune hepatitis in diverse ethnic populations and geographical regions. Expert Rev Gastroenterol Hepatol 2013;7:365385.

18. Alvarez F, Berg PA, Bianchi FB, et al. International Autoimmune Hepatitis Group Report: review of criteria for diagnosis of autoimmune hepatitis. J Hepatol 1999;31:929-938.

19. Hennes EM, Zeniya M, Czaja AJ, et al; International Autoimmune Hepatitis Group. Simplified criteria for the diagnosis of autoimmune hepatitis. Hepatology 2008;48:169-176.

20. Rigopoulou EI, Dalekos G, Bogdanos DP. How common are connective tissue disorders in patients with autoimmune hepatitis? Semin Arthritis Rheum 2007;36:332.

21. Teufel A, Weinmann A, Kahaly GJ, et al. Concurrent autoimmune diseases in patients with autoimmune hepatitis. J Clin Gastroenterol 2010;44:208-213.

22. Obermayer-Straub P, Perheentupa J, Braun S, et al. Hepatic autoantigens in patients with autoimmune polyendocrinopathycandidiasis-ectodermal dystrophy. Gastroenterology 2001;121:668677.

23. Muratori P, Granito A, Quarneti C, et al. Autoimmune hepatitis in Italy: the Bologna experience. J Hepatol 2009;50:1210-1218.

24. Peng M, Li Y, Zhang M, et al. Clinical features in different age groups of patients with autoimmune hepatitis. Exp Ther Med 2014;7:145-148.

25. Al-Chalabi T, Boccato S, Portmann BC, McFarlane IG, Heneghan MA. Autoimmune hepatitis (AIH) in the elderly: a systematic retrospective analysis of a large group of consecutive patients with definite $\mathrm{AIH}$ followed at a tertiary referral centre. J Hepatol 2006;45:575-583.

26. Grønbæk L, Vilstrup H, Pedersen L, Christensen K, Jepsen P. Family occurrence of autoimmune hepatitis: A Danish nationwide registry-based cohort study. J Hepatol 2018;69:873-877.

27. Schramm C, Wahl I, Weiler-Normann C, et al. Health-related quality of life, depression, and anxiety in patients with autoimmune hepatitis. J Hepatol 2014;60:618-624.

28. Stravitz RT, Lefkowitch JH, Fontana RJ, et al; Acute Liver Failure Study Group. Autoimmune acute liver failure: proposed clinical and histological criteria. Hepatology 2011;53:517-526.

29. Muratori P, Carbone M, Stangos G, et al. Clinical and prognostic implications of acute onset of autoimmune hepatitis: An Italian multicentre study. Dig Liver Dis 2018;50:698-702.

30. Joshita S, Yoshizawa K, Umemura T, et al; Japan Autoimmune Hepatitis Study Group (JAIHSG). Clinical features of autoimmune hepatitis with acute presentation: a Japanese nationwide survey. J Gastroenterol 2018;53:1079-1088.

31. Takahashi H, Zeniya M. Acute presentation of autoimmune hepatitis: Does it exist? A published work review. Hepatol Res 2011;41:498-504.

32. Karkhanis J, Verna EC, Chang MS, et al; Acute Liver Failure Study Group. Steroid use in acute liver failure. Hepatology
2014;59:612-621.

33. Feld JJ, Dinh H, Arenovich T, Marcus VA, Wanless IR, Heathcote EJ. Autoimmune hepatitis: effect of symptoms and cirrhosis on natural history and outcome. Hepatology 2005;42:53-62.

34. Zachou K, Gatselis N, Papadamou G, Rigopoulou EI, Dalekos GN. Mycophenolate for the treatment of autoimmune hepatitis: prospective assessment of its efficacy and safety for induction and maintenance of remission in a large cohort of treatment-naïve patients. J Hepatol 2011;55:636-646.

35. Landeira G, Morise S, Fassio E, et al. Effect of cirrhosis at baseline on the outcome of type 1 autoimmune hepatitis. Ann Hepatol 2012;11:100-106.

36. Ngu JH, Gearry RB, Frampton CM, Stedman CA. Predictors of poor outcome in patients with autoimmune hepatitis: a populationbased study. Hepatology 2013;57:2399-2406.

37. Westbrook RH, Yeoman AD, Kriese S, Heneghan MA. Outcomes of pregnancy in women with autoimmune hepatitis. J Autoimmun 2012;38:J239-J244.

38. Terrabuio DR, Abrantes-Lemos CP, Carrilho FJ, Cançado EL. Follow-up of pregnant women with autoimmune hepatitis: the disease behavior along with maternal and fetal outcomes. J Clin Gastroenterol 2009;43:350-356.

39. Danielsson Borssén, Wallerstedt S, Nyhlin N, et al. Pregnancy and childbirth in women with autoimmune hepatitis is safe, even in compensated cirrhosis. Scand J Gastroenterol 2016;51:479-485.

40. Castiella A, Zapata E, Lucena MI, Andrade RJ. Drug-induced autoimmune liver disease: a diagnostic dilemma of an increasingly reported disease. World J Hepatol 2014;6:160-168.

41. Appleyard S, Saraswati R, Gorard DA. Autoimmune hepatitis triggered by nitrofurantoin: a case series. J Med Case Rep 2010;4:311.

42. Saitis A, Gatselis N, Zachou K, Dalekos GN. Use of TNFa antagonists in refractory AIH: revealing the unforeseen. J Hepatol 2013;59:197-198.

43. Kern E, VanWagner LB, Yang GY, Rinella ME. Liraglutide-induced autoimmune hepatitis. JAMA Intern Med 2014;174:984-987.

44. Arvaniti P, Zachou K, Koukoulis GK, Dalekos GN. Postinfantile giant cell hepatitis with features of acute severe autoimmune hepatitis probably triggered by diclofenac in a patient with primary myelofibrosis. Case Reports Hepatol 2018;2018:9793868.

45. Suzuki A, Brunt EM, Kleiner DE, et al. The use of liver biopsy evaluation in discrimination of idiopathic autoimmune hepatitis versus drug-induced liver injury. Hepatology 2011;54:931-939.

46. Fontana RJ, Seeff LB, Andrade RJ, et al. Standardization of nomenclature and causality assessment in drug-induced liver injury: summary of a clinical research workshop. Hepatology 2010;52:730-742.

47. Björnsson E, Talwalkar J, Treeprasertsuk S, et al. Drug-induced autoimmune hepatitis: clinical characteristics and prognosis. Hepatology 2010;51:2040-2048.

48. Chalasani N, Fontana RJ, Bonkovsky HL, et al; Drug Induced Liver Injury Network (DILIN). Causes, clinical features, and outcomes from a prospective study of drug-induced liver injury in the United States. Gastroenterology 2008;135:1924-1934, 1934.e1-e4.

49. Vento S, Cainelli F. Is there a role for viruses in triggering autoimmune hepatitis? Autoimmun Rev 2004;3:61-69.

50. Zellos A, Spoulou V, Roma-Giannikou E, Karentzou O, Dalekos GN, Theodoridou M. Autoimmune hepatitis type-2 and Epstein-Barr virus infection in a toddler: Art of facts or an artifact? Ann Hepatol 2013;12:147-151.

51. Dalekos GN, Wedemeyer H, Obermayer-Straub P, et al. Epitope mapping of cytochrome P4502D6 autoantigen in patients with chronic hepatitis C during alpha-interferon treatment. J Hepatol 1999;30:366-375.

52. Mieli-Vergani G, Vergani D. De novo autoimmune hepatitis after liver transplantation. J Hepatol 2004;40:3-7. 
53. Montano-Loza AJ, Vargas-Vorackova F, Ma M, et al. Incidence and risk factors associated with de novo autoimmune hepatitis after liver transplantation. Liver Int 2012;32:1426-1433.

54. Kwon JH, Hanouneh IA, Allende D, et al. De novo autoimmune hepatitis following liver transplantation. Transplant Proc 2018;50:1451-1456.

55. Teufel A, Weinmann A, Centner C, et al. Hepatocellular carcinoma in patients with autoimmune hepatitis. World $J$ Gastroenterol 2009;15:578-582.

56. Yeoman AD, Al-Chalabi T, Karani JB, et al. Evaluation of risk factors in the development of hepatocellular carcinoma in autoimmune hepatitis: implications for follow-up and screening. Hepatology 2008;48:863-870.

57. Ngu JH, Gearry RB, Frampton CM, Stedman CA. Mortality and the risk of malignancy in autoimmune liver diseases: a populationbased study in Canterbury, New Zealand. Hepatology 2012;55:522529.

58. Migita K, Watanabe Y, Jiuchi Y, et al; Japanese NHO-Livernetwork study group. Hepatocellular carcinoma and survival in patients with autoimmune hepatitis (Japanese National Hospital Organization-autoimmune hepatitis prospective study). Liver Int 2012;32:837-844.

59. Boberg KM, Chapman RW, Hirschfield GM, Lohse AW, Manns MP, Schrumpf E; International Autoimmune Hepatitis Group. Overlap syndromes: the International Autoimmune Hepatitis Group (IAIHG) position statement on a controversial issue. J Hepatol 2011;54:374-385.

60. European Association for the Study of the Liver. EASL Clinical Practice Guidelines: Autoimmune hepatitis. J Hepatol 2015;63:9711004.

61. Chazouillères $\mathrm{O}$, Wendum $\mathrm{D}$, Serfaty L, Montembault S, Rosmorduc O, Poupon R. Primary biliary cirrhosis-autoimmune hepatitis overlap syndrome: clinical features and response to therapy. Hepatology 1998;28:296-301.

62. European Association for the Study of the Liver. EASL Clinical Practice Guidelines: The diagnosis and management of patients with primary biliary cholangitis. J Hepatol 2017;67:145-172.

63. Gregorio GV, Portmann B, Karani J, et al. Autoimmune hepatitis/ sclerosing cholangitis overlap syndrome in childhood: a 16-year prospective study. Hepatology 2001;33:544-553.

64. Rojas CP, Bodicharla R, Campuzano-Zuluaga G, Hernandez L, Rodriguez MM. Autoimmune hepatitis and primary sclerosing cholangitis in children and adolescents. Fetal Pediatr Pathol 2014;33:202-209.

65. Papamichalis PA, Zachou K, Koukoulis GK, et al. The revised international autoimmune hepatitis score in chronic liver diseases including autoimmune hepatitis/overlap syndromes and autoimmune hepatitis with concurrent other liver disorders. J Autoimmune Dis 2007;4:3.

66. Lüth S, Kanzler S, Frenzel C, et al. Characteristics and longterm prognosis of the autoimmune hepatitis/primary sclerosing cholangitis overlap syndrome. J Clin Gastroenterol 2009;43:75-80.

67. Lewin M, Vilgrain V, Ozenne V, et al. Prevalence of sclerosing cholangitis in adults with autoimmune hepatitis: a prospective magnetic resonance imaging and histological study. Hepatology 2009;50:528-537.

68. Yasui S, Fujiwara K, Yonemitsu Y, Oda S, Nakano M, Yokosuka O. Clinicopathological features of severe and fulminant forms of autoimmune hepatitis. J Gastroenterol 2011;46:378-390.

69. Mieli-Vergani G, Vergani D, Baumann U, et al. Diagnosis and management of pediatric autoimmune liver disease: ESPGHAN hepatology committee position statement. J Pediatr Gastroenterol Nutr 2018;66:345-360.

70. Terziroli Beretta-Piccoli B, Mieli-Vergani G, Vergani D. Serology in autoimmune hepatitis: A clinical-practice approach. Eur J Intern Med 2018;48:35-43.
71. Dalekos GN, Zachou K, Liaskos C, Gatselis N. Autoantibodies and defined target autoantigens in autoimmune hepatitis: an overview. Eur J Intern Med 2002;13:293-303.

72. Zachou K, Rigopoulou E, Dalekos GN. Autoantibodies and autoantigens in autoimmune hepatitis: important tools in clinical practice and to study pathogenesis of the disease. J Autoimmune Dis 2004;1:2.

73. Liaskos C, Bogdanos DP, Davies ET, Dalekos GN. Diagnostic relevance of anti-filamentous actin antibodies in autoimmune hepatitis. J Clin Pathol 2007;60:107-108.

74. Dalekos GN, Makri E, Loges S, et al. Increased incidence of antiLKM autoantibodies in a consecutive cohort of hepatitis $C$ patients from central Greece. Eur J Gastroenterol Hepatol 2002;14:35-42.

75. Ferri S, Muratori L, Quarneti C, et al. Clinical features and effect of antiviral therapy on anti-liver/kidney microsomal antibody type 1 positive chronic hepatitis C. J Hepatol 2009;50:1093-1101.

76. Crivelli O, Lavarini C, Chiaberge E, et al. Microsomal autoantibodies in chronic infection with the HBsAg associated delta (delta) agent. Clin Exp Immunol 1983;54:232-238.

77. Fabien N, Desbos A, Bienvenu J, Magdalou J. Autoantibodies directed against the UDP-glucuronosyltransferases in human autoimmune hepatitis. Autoimmun Rev 2004;3:1-9.

78. European Association for the Study of the Liver. EASL Recommendations on Treatment of Hepatitis C 2018. J Hepatol 2018;69:461-511.

79. Zachou K, Gampeta S, Gatselis NK, et al. Anti-SLA/LP alone or in combination with anti-Ro52 and fine specificity of antiRo52 antibodies in patients with autoimmune hepatitis. Liver Int 2015;35:660-672.

80. Liaskos C, Bogdanos DP, Rigopoulou EI, et al. Antibody responses specific for soluble liver antigen co-occur with Ro-52 autoantibodies in patients with autoimmune hepatitis. $J$ Hepatol 2007;46:S250.

81. Eyraud V, Chazouilleres O, Ballot E, Corpechot C, Poupon R, Johanet C. Significance of antibodies to soluble liver antigen/liver pancreas: a large French study. Liver Int 2009;29:857-864.

82. Montano-Loza AJ, Shums Z, Norman GL, Czaja AJ. Prognostic implications of antibodies to Ro/SSA and soluble liver antigen in type 1 autoimmune hepatitis. Liver Int 2012;32:85-92.

83. Wies I, Brunner S, Henninger J, et al. Identification of target antigen for SLA/LP autoantibodies in autoimmune hepatitis. Lancet 2000;355:1510-1515.

84. Palioura S, Sherrer RL, Steitz TA, Söll D, Simonovic M. The human SepSecS-tRNASec complex reveals the mechanism of selenocysteine formation. Science 2009;325:321-325.

85. Ma Y, Okamoto M, Thomas MG, et al. Antibodies to conformational epitopes of soluble liver antigen define a severe form of autoimmune liver disease. Hepatology 2002;35:658-664.

86. Gatselis NK, Dalekos GN. Molecular diagnostic testing for primary biliary cholangitis. Expert Rev Mol Diagn 2016;16:1001-1010.

87. O'Brien C, Joshi S, Feld JJ, Guindi M, Dienes HP, Heathcote EJ. Long-term follow-up of antimitochondrial antibody-positive autoimmune hepatitis. Hepatology 2008;48:550-556.

88. Montano-Loza AJ, Carpenter HA, Czaja AJ. Frequency, behavior, and prognostic implications of antimitochondrial antibodies in type 1 autoimmune hepatitis. J Clin Gastroenterol 2008;42:1047-1053.

89. Nezu S, Tanaka A, Yasui H, et al. Presence of antimitochondrial autoantibodies in patients with autoimmune hepatitis. J Gastroenterol Hepatol 2006;21:1448-1454.

90. Muratori P, Efe C, Muratori L, et al. Clinical implications of antimitochondrial antibody seropositivity in autoimmune hepatitis: a multicentre study. Eur J Gastroenterol Hepatol 2017;29:777-780.

91. Liaskos C, Bogdanos DP, Rigopoulou EI, Dalekos GN. Development of antimitochondrial antibodies in patients with autoimmune hepatitis: art of facts or an artifact? J Gastroenterol Hepatol 2007;22:454-455. 
92. Dinani AM, Fischer SE, Mosko J, Guindi M, Hirschfield GM. Patients with autoimmune hepatitis who have antimitochondrial antibodies need long-term follow-up to detect late development of primary biliary cirrhosis. Clin Gastroenterol Hepatol 2012;10:682-684.

93. Renaudineau Y, Deocharan B, Jousse S, Renaudineau E, Putterman C, Youinou P. Anti-alpha-actinin antibodies: a new marker of lupus nephritis. Autoimmun Rev 2007;6:464-468.

94. Oikonomou KG, Zachou K, Dalekos GN. Alpha-actinin: a multidisciplinary protein with important role in B-cell driven autoimmunity. Autoimmun Rev 2011;10:389-396.

95. Guéguen P, Dalekos G, Nousbaum JB, et al. Double reactivity against actin and alpha-actinin defines a severe form of autoimmune hepatitis type 1. J Clin Immunol 2006;26:495-505.

96. Renaudineau Y, Dalekos GN, Guéguen P, Zachou K, Youinou P. Anti-alpha-actinin antibodies cross-react with anti-ssDNA antibodies in active autoimmune hepatitis. Clin Rev Allergy Immunol 2008;34:321-325.

97. Zachou K, Oikonomou K, Renaudineau Y, et al. Anti- $\alpha$ actinin antibodies as new predictors of response to treatment in autoimmune hepatitis type 1. Aliment Pharmacol Ther 2012;35:116-125.

98. Dienes HP, Erberich H, Dries V, Schirmacher P, Lohse A. Autoimmune hepatitis and overlap syndromes. Clin Liver Dis 2002;6:349-362, vi.

99. Zen Y, Notsumata K, Tanaka N, Nakanuma Y. Hepatic centrilobular zonal necrosis with positive antinuclear antibody: a unique subtype or early disease of autoimmune hepatitis? Hum Pathol 2007;38:1669-1675.

100. Czaja AJ, Muratori P, Muratori L, Carpenter HA, Bianchi FB. Diagnostic and therapeutic implications of bile duct injury in autoimmune hepatitis. Liver Int 2004;24:322-329.

101. Hartl J, Ehlken H, Sebode M, et al. Usefulness of biochemical remission and transient elastography in monitoring disease course in autoimmune hepatitis. J Hepatol 2018;68:754-763.

102. Gutkowski K, Hartleb M, Kacperek-Hartleb T, et al. Laboratorybased scoring system for prediction of hepatic inflammatory activity in patients with autoimmune hepatitis. Liver Int 2013;33:1370-1377.

103. Dalekos GN, Bogdanos DP, Neuberger J. Celiac disease-related autoantibodies in end-stage autoimmune liver diseases: what is the message? Liver Int 2008;28:426-428.

104. Kaya M, Angulo P, Lindor KD. Overlap of autoimmune hepatitis and primary sclerosing cholangitis: an evaluation of a modified scoring system. J Hepatol 2000;33:537-542.

105. Talwalkar JA, Keach JC, Angulo P, Lindor KD. Overlap of autoimmune hepatitis and primary biliary cirrhosis: an evaluation of a modified scoring system. Am J Gastroenterol 2002;97:1191-1197.

106. Gatselis N, Zachou K, Papamichalis P, et al. Comparison of simplified score with the revised original score for the diagnosis of autoimmune hepatitis: a new or a complementary diagnostic score? Dig Liver Dis 2010;42:807-812.

107. Qiu D, Wang Q, Wang H, et al. Validation of the simplified criteria for diagnosis of autoimmune hepatitis in Chinese patients. J Hepatol 2011;54:340-347.

108. Yeoman AD, Westbrook RH, Al-Chalabi T, et al. Diagnostic value and utility of the simplified International Autoimmune Hepatitis Group (IAIHG) criteria in acute and chronic liver disease. Hepatology 2009;50:538-545.

109. Lohse AW. Recognizing autoimmune hepatitis: scores help, but no more. J Hepatol 2011;54:193-194.

110. Yamamoto K, Miyake Y, Ohira H, et al; Intractable Liver and Biliary Diseases Study Group of Japan. Prognosis of autoimmune hepatitis showing acute presentation. Hepatol Res 2013;43:630-638.
111. Fujiwara K, Yasui S, Tawada A, Fukuda Y, Nakano M, Yokosuka O. Diagnostic value and utility of the simplified International Autoimmune Hepatitis Group criteria in acute-onset autoimmune hepatitis. Liver Int 2011;31:1013-1020.

112. Zachou K, Arvaniti P, Azariadis K, et al. Prompt initiation of high-dose i.v. corticosteroids seems to prevent progression to liver failure in patients with original acute severe autoimmune hepatitis. Hepatol Res 2018 Sep 24 [Epub ahead of print].

113. Kalafateli M, Triantos C, Tsamandas A, Dalekos GN. Spontaneous cirrhosis regression in an IFN-beta-induced AIH-like syndrome following drug withdrawal: art of facts or artifacts? Eur J Case Rep Intern Med 2016;3.

114. Kirk AP, Jain S, Pocock S, Thomas HC, Sherlock S. Late results of the Royal Free Hospital prospective controlled trial of prednisolone therapy in hepatitis B surface antigen negative chronic active hepatitis. Gut 1980;21:78-83.

115. Lamers MM, van Oijen MG, Pronk M, Drenth JP. Treatment options for autoimmune hepatitis: a systematic review of randomized controlled trials. J Hepatol 2010;53:191-198.

116. Dufour JF, Zimmermann M, Reichen J. Severe autoimmune hepatitis in patients with previous spontaneous recovery of a flare. J Hepatol 2002;37:748-752.

117. Czaja AJ. Features and consequences of untreated type 1 autoimmune hepatitis. Liver Int 2009;29:816-823.

118. Lohse AW, Mieli-Vergani G. Autoimmune hepatitis. J Hepatol 2011;55:171-182.

119. Schramm C, Weiler-Normann C, Wiegard C, Hellweg S, Müller S, Lohse AW. Treatment response in patients with autoimmune hepatitis. Hepatology 2010;52:2247-2248.

120. Wang Q, Qiu D, Ma X. Early normalisation of aminotransferase predicts complete biochemical remission in autoimmune hepatitis patients. Aliment Pharmacol Ther 2011;34:107-109.

121. Czaja AJ. Safety issues in the management of autoimmune hepatitis. Expert Opin Drug Saf 2008;7:319-333.

122. Heneghan MA, Allan ML, Bornstein JD, Muir AJ, Tendler DA. Utility of thiopurine methyltransferase genotyping and phenotyping, and measurement of azathioprine metabolites in the management of patients with autoimmune hepatitis. J Hepatol 2006;45:584-591.

123. Czaja AJ, Carpenter HA. Thiopurine methyltransferase deficiency and azathioprine intolerance in autoimmune hepatitis. Dig Dis Sci 2006;51:968-975.

124. Hindorf U, Jahed K, Bergquist A, et al. Characterisation and utility of thiopurine methyltransferase and thiopurine metabolite measurements in autoimmune hepatitis. $J$ Hepatol 2010;52:106-111.

125. Czaja AJ. Current and prospective pharmacotherapy for autoimmune hepatitis. Expert Opin Pharmacother 2014; 15:1715-1736.

126. van Gerven NM, Verwer BJ, Witte BI, et al; Dutch Autoimmune Hepatitis Working Group. Relapse is almost universal after withdrawal of immunosuppressive medication in patients with autoimmune hepatitis in remission. J Hepatol 2013;58:141-147.

127. Hlivko JT, Shiffman ML, Stravitz RT, et al. A single center review of the use of mycophenolate mofetil in the treatment of autoimmune hepatitis. Clin Gastroenterol Hepatol 2008;6:1036-1040.

128. Zachou K, Gatselis NK, Arvaniti P, et al. A real-world study focused on the long-term efficacy of mycophenolate mofetil as first-line treatment of autoimmune hepatitis. Aliment Pharmacol Ther 2016;43:1035-1047.

129. Dalekos GN, Zachou K. Editorial: autoimmune hepatitisidentifying options for treatment. Authors' reply. Aliment Pharmacol Ther 2016;43:1237-1238.

130. Manns MP, Woynarowski M, Kreisel W, et al; European AIHBUC-Study Group. Budesonide induces remission more 
effectively than prednisone in a controlled trial of patients with autoimmune hepatitis. Gastroenterology 2010;139:1198-1206.

131. Liberal R, de Boer YS, Andrade RJ, et al; International Autoimmune Hepatitis Group (IAIHG). Expert clinical management of autoimmune hepatitis in the real world. Aliment Pharmacol Ther 2017;45:723-732.

132. Wiegand J, Schüler A, Kanzler S, et al. Budesonide in previously untreated autoimmune hepatitis. Liver Int 2005;25:927-934.

133. Efe C, Ozaslan E, Kav T, et al. Liver fibrosis may reduce the efficacy of budesonide in the treatment of autoimmune hepatitis and overlap syndrome. Autoimmun Rev 2012;11:330-334.

134. Woynarowski M, Nemeth A, Baruch Y, et al; European Autoimmune Hepatitis-Budesonide Study Group. Budesonide versus prednisone with azathioprine for the treatment of autoimmune hepatitis in children and adolescents. J Pediatr 2013;163:1347-1353.e1.

135. Allison AC. Mechanisms of action of mycophenolate mofetil. Lupus 2005;14 Suppl 1:s2-s8.

136. Demirkiran A, Sewgobind VD, van der Weijde J, et al. Conversion from calcineurin inhibitor to mycophenolate mofetil-based immunosuppression changes the frequency and phenotype of CD4+FOXP3+ regulatory T cells. Transplantation 2009;87:10621068.

137. Miroux C, Morales O, Ouaguia L, et al. Corticosteroids do not reverse the inhibitory effect of cyclosporine on regulatory T-cell activity in contrast to mycophenolate mofetil. Transplant Proc 2012;44:2834-2839.

138. Lee J, Kim MS, Kim EY, et al. Mycophenolate mofetil promotes down-regulation of expanded $\mathrm{B}$ cells and production of TNFalpha in an experimental murine model of colitis. Cytokine 2008;44:49-56.

139. Taubert R, Hardtke-Wolenski M, Noyan F, et al. Intrahepatic regulatory $\mathrm{T}$ cells in autoimmune hepatitis are associated with treatment response and depleted with current therapies. J Hepatol 2014;61:1106-1114.

140. Chen YY, Jeffery HC, Hunter S, et al. Human intrahepatic regulatory $\mathrm{T}$ cells are functional, require IL-2 from effector cells for survival, and are susceptible to Fas ligand-mediated apoptosis. Hepatology 2016;64:138-150.

141. Diestelhorst J, Junge N, Schlue J, et al. Pediatric autoimmune hepatitis shows a disproportionate decline of regulatory $\mathrm{T}$ cells in the liver and of IL-2 in the blood of patients undergoing therapy. PLoS One 2017;12:e0181107.

142. Czaja AJ. Rapidity of treatment response and outcome in type 1 autoimmune hepatitis. J Hepatol 2009;51:161-167.

143. Muratori P, Granito A, Pappas G, Muratori L. Validation of simplified diagnostic criteria for autoimmune hepatitis in Italian patients. Hepatology 2009;49:1782-1783; author reply 1783.

144. Manns MP, Jaeckel E, Taubert R. Budesoinide in autoimmune hepatitis: The right drug at the right time for the right patient. Clin Gastroenterol Hepatol 2018;16:186-189.

145. Czaja AJ, Lindor KD. Failure of budesonide in a pilot study of treatment-dependent autoimmune hepatitis. Gastroenterology 2000;119:1312-1316.

146. Lohse AW, Gil H. Reactivation of autoimmune hepatitis during budesonide monotherapy, and response to standard treatment. J Hepatol 2011;54:837-839.

147. Johnson PJ, McFarlane IG, Williams R. Azathioprine for longterm maintenance of remission in autoimmune hepatitis. $N$ Engl J Med 1995;333:958-963.

148. Czaja AJ, Ludwig J, Baggenstoss AH, Wolf A. Corticosteroidtreated chronic active hepatitis in remission: uncertain prognosis of chronic persistent hepatitis. N Engl J Med 1981;304:5-9.

149. Czaja AJ, Menon KV, Carpenter HA. Sustained remission after corticosteroid therapy for type 1 autoimmune hepatitis: a retrospective analysis. Hepatology 2002;35:890-897.
150. Verma S, Gunuwan B, Mendler M, Govindrajan S, Redeker A. Factors predicting relapse and poor outcome in type I autoimmune hepatitis: role of cirrhosis development, patterns of transaminases during remission and plasma cell activity in the liver biopsy. Am J Gastroenterol 2004;99:1510-1516.

151. Kanzler S, Gerken G, Löhr H, Galle PR, Meyer zum Büschenfelde KH, Lohse AW. Duration of immunosuppressive therapy in autoimmune hepatitis. J Hepatol 2001;34:354-355.

152. Montano-Loza AJ, Carpenter HA, Czaja AJ. Improving the end point of corticosteroid therapy in type 1 autoimmune hepatitis to reduce the frequency of relapse. Am J Gastroenterol 2007;102:1005-1012.

153. Hoeroldt B, McFarlane E, Dube A, et al. Long-term outcomes of patients with autoimmune hepatitis managed at a nontransplant center. Gastroenterology 2011;140:1980-1989.

154. Montano-Loza AJ, Carpenter HA, Czaja AJ. Consequences of treatment withdrawal in type 1 autoimmune hepatitis. Liver Int 2007;27:507-515.

155. Hartl J, Ehlken H, Weiler-Normann C, et al. Patient selection based on treatment duration and liver biochemistry increases success rates after treatment withdrawal in autoimmune hepatitis. J Hepatol 2015;62:642-646.

156. Lüth S, Herkel J, Kanzler S, et al. Serologic markers compared with liver biopsy for monitoring disease activity in autoimmune hepatitis. J Clin Gastroenterol 2008;42:926-930.

157. European Association for the Study of the Liver. EASL 2017 Clinical Practice Guidelines on the management of hepatitis B virus infection. J Hepatol 2017;67:370-398.

158. Dalekos GN, Goulis I, Manolakopoulos S, Papaevangelou V, Papatheodoridis G. Clinical Practice Guidelines for the Management of Hepatitis B Virus Infection. Hellenic Center for Disease Control and Prevention, Hellenic Ministry of Health, Athens, December 2017 (online edition, www.keelpno.gr).

159. Selvarajah V, Montano-Loza AJ, Czaja AJ. Systematic review: managing suboptimal treatment responses in autoimmune hepatitis with conventional and nonstandard drugs. Aliment Pharmacol Ther 2012;36:691-707.

160. Deutsch M, Emmanuel T, Koskinas J. Autoimmune hepatitis or Wilson's disease, a clinical dilemma. Hepat Mon 2013;13:e7872.

161. Azariadi K, Arvaniti P, Gatselis NK, Koukoulis GK, Dalekos GN, Zachou K. Severe acute non-A, non-B, non-C hepatitis with autoimmune features: Consider acute hepatitis E virus (HEV) infection not just autoimmune hepatitis (AIH). $9^{\text {th }}$ International Congress of Internal Medicine, Athens, March 9-11, 2017, Abstract Book p. 23.

162. Ichai P, Duclos-Vallee JC, Guettier C, et al. Usefulness of corticosteroids for the treatment of severe and fulminant forms of autoimmune hepatitis. Liver Transpl 2007;13:996-1003.

163. Yeoman AD, Westbrook RH, Zen Y, et al. Prognosis of acute severe autoimmune hepatitis (AS-AIH): the role of corticosteroids in modifying outcome. J Hepatol 2014;61:876-882.

164. Verma S, Maheshwari A, Thuluvath P. Liver failure as initial presentation of autoimmune hepatitis: clinical characteristics, predictors of response to steroid therapy, and outcomes. Hepatology 2009;49:1396-1397.

165. Wendon, J, Cordoba J, Dhawan A, et al; EASL Governing Board representative. EASL Clinical Practical Guidelines on the management of acute (fulminant) liver failure. $J$ Hepatol 2017;66:1047-1081.

166. Moenne-Loccoz R, Severac F, Baumert TF, Habersetzer F. Usefulness of corticosteroids as first-line therapy in patients with acute severe autoimmune hepatitis. J Hepatol 2016;65:444-446.

167. Yeoman AD, Westbrook RH, Zen Y, et al. Early predictors of corticosteroid treatment failure in icteric presentations of autoimmune hepatitis. Hepatology 2011;53:926-934.

168. Montano-Loza AJ, Carpenter HA, Czaja AJ. Features associated with treatment failure in type 1 autoimmune hepatitis and 
predictive value of the model of end-stage liver disease. Hepatology 2007;46:1138-1145.

169. Sonthalia N, Rathi M, Jain S, et al. Natural history and treatment outcomes of severe autoimmune hepatitis. J Clin Gastroenterol 2017;51:548-556.

170. Potts JR, Verma S. Optimizing management in autoimmune hepatitis with liver failure at initial presentation. World $J$ Gastroenterol 2011;17:2070-2075.

171. De M E, Coilly A, Houssel-Debry P, et al. Treatment and prognosis of acute severe autoimmune hepatitis. I Hepatol 2017;66(Suppl 1):S4. [Abstract]

172. Weiler-Normann C, Lohse AW. Acute autoimmune hepatitis: many open questions. J Hepatol 2014;61:727-729.

173. Dhaliwal HK, Anderson R, Thornhill EL, et al. Clinical significance of azathioprine metabolites for the maintenance of remission in autoimmune hepatitis. Hepatology 2012;56:1401-1408.

174. Floreani A, Liberal R, Vergani D, Mieli-Vergani G. Autoimmune hepatitis: Contrasts and comparisons in children and adults - a comprehensive review. J Autoimmun 2013;46:7-16.

175. Kerkar N, Annunziato RA, Foley L, et al. Prospective analysis of nonadherence in autoimmune hepatitis: a common problem. J Pediatr Gastroenterol Nutr 2006;43:629-634.

176. Kelly D. Theory to reality: the role of the transition nurse coordinator. Br J Nurs 2014;23:888, 890, 892-894.

177. Sockalingam S, Blank D, Abdelhamid N, Abbey SE, Hirschfield GM. Identifying opportunities to improve management of autoimmune hepatitis: evaluation of drug adherence and psychosocial factors. J Hepatol 2012;57:1299-1304.

178. Chatur N, Ramji A, Bain VG, et al. Transplant immunosuppressive agents in non-transplant chronic autoimmune hepatitis: the Canadian association for the study of liver (CASL) experience with mycophenolate mofetil and tacrolimus. Liver Int 2005;25:723-727.

179. Inductivo-Yu I, Adams A, Gish RG, et al. Mycophenolate mofetil in autoimmune hepatitis patients not responsive or intolerant to standard immunosuppressive therapy. Clin Gastroenterol Hepatol 2007;5:799-802.

180. Aw MM, Dhawan A, Samyn M, Bargiota A, Mieli-Vergani G. Mycophenolate mofetil as rescue treatment for autoimmune liver disease in children: a 5-year follow-up. J Hepatol 2009;51:156-160.

181. Wolf DC, Bojito L, Facciuto M, Lebovics E. Mycophenolate mofetil for autoimmune hepatitis: a single practice experience. Dig Dis Sci 2009;54:2519-2522.

182. Czaja AJ, Carpenter HA. Empiric therapy of autoimmune hepatitis with mycophenolate mofetil: comparison with conventional treatment for refractory disease. J Clin Gastroenterol 2005;39:819-825.

183. Hennes EM, Oo YH, Schramm C, et al. Mycophenolate mofetil as second line therapy in autoimmune hepatitis? Am J Gastroenterol 2008;103:3063-3070.

184. Sharzehi K, Huang MA, Schreibman IR, Brown KA. Mycophenolate mofetil for the treatment of autoimmune hepatitis in patients refractory or intolerant to conventional therapy. Can J Gastroenterol 2010;24:588-592.

185. Baven-Pronk AM, Coenraad MJ, van Buuren HR, et al. The role of mycophenolate mofetil in the management of autoimmune hepatitis and overlap syndromes. Aliment Pharmacol Ther 2011;34:335-343.

186. Roberts SK, Lim R, Strasser S, et al; ALA Clinical Research Network. Efficacy and safety of mycophenolate mofetil in patients with autoimmune hepatitis and suboptimal outcomes after standard therapy. Clin Gastroenterol Hepatol 2018;16:268-277.

187. Efe C, Hagström H, Ytting H, et al. Efficacy and safety of mycophenolate mofetil and tacrolimus as second-line therapy for patients with autoimmune hepatitis. Clin Gastroenterol Hepatol 2017; 15:1950-1956.

188. Peiseler $M$, Liebscher $T$, Sebode $M$, et al. Efficacy and limitations of budesonide as a second-line treatment for patients with autoimmune hepatitis. Clin Gastroenterol Hepatol 2018;16:260-267.

189. Legué C, Legros L, Kammerer-Jacquet S, et al. Safety and efficacy of 6-thioguanine as a second-line treatment for autoimmune hepatitis. Clin Gastroenterol Hepatol 2018;16:290-291.

190. Haridy J, Nicoll A, Sood S. Methotrexate therapy for autoimmune hepatitis. Clin Gastroenterol Hepatol 2018;16:288-289.

191. Sciveres M, Caprai S, Palla G, Ughi C, Maggiore G. Effectiveness and safety of ciclosporin as therapy for autoimmune diseases of the liver in children and adolescents. Aliment Pharmacol Ther 2004; 19:209-217.

192. de Boer YS, van Gerven NM, de Boer NK, Mulder CJ, Bouma G, van Nieuwkerk CM. Allopurinol safely and effectively optimises thiopurine metabolites in patients with autoimmune hepatitis. Aliment Pharmacol Ther 2013;37:640-646.

193. Burak KW, Swain MG, Santodomingo-Garzon T, et al. Rituximab for the treatment of patients with autoimmune hepatitis who are refractory or intolerant to standard therapy. Can J Gastroenterol 2013;27:273-280.

194. Weiler-Normann C, Schramm C, Quaas A, et al. Infliximab as a rescue treatment in difficult-to-treat autoimmune hepatitis. J Hepatol 2013;58:529-534.

195. Chen J, Eslick GD, Weltman M. Systematic review with metaanalysis: clinical manifestations and management of autoimmune hepatitis in the elderly. Aliment Pharmacol Ther 2014;39:117-124.

196. Miyake Y, Iwasaki Y, Takaki A, Kobashi H, Sakaguchi K, Shiratori Y. Clinical features of Japanese elderly patients with type 1 autoimmune hepatitis. Intern Med 2007;46:1945-1949.

197. Azariadi K, Arvaniti P, Zachou K, Saitis AI, Dalekos GN, Gatselis N. Autoimmune hepatitis: Impact of age at disease onset on disease severity, outcome and response to treatment. Hepatology 2016;64:820A. [Abstract]

198. Chazouillères O, Wendum D, Serfaty L, Rosmorduc O, Poupon R. Long term outcome and response to therapy of primary biliary cirrhosis-autoimmune hepatitis overlap syndrome. J Hepatol 2006;44:400-406.

199. Ozaslan E, Efe C, Heurgué-Berlot A, et al. Factors associated with response to therapy and outcome of patients with primary biliary cirrhosis with features of autoimmune hepatitis. Clin Gastroenterol Hepatol 2014;12:863-869.

200. Poupon R, Chazouilleres O, Corpechot C, Chrétien Y. Development of autoimmune hepatitis in patients with typical primary biliary cirrhosis. Hepatology 2006;44:85-90.

201. European Association for the Study of the Liver. EASL Clinical Practice Guidelines: management of cholestatic liver diseases. J Hepatol 2009;51:237-267.

202. Floreani A, Rizzotto ER, Ferrara F, et al. Clinical course and outcome of autoimmune hepatitis/primary sclerosing cholangitis overlap syndrome. Am J Gastroenterol 2005;100:1516-1522.

203. Zenouzi R, Lohse AW. Long-term outcome in PSC/AIH "overlap syndrome": does immunosuppression also treat the PSC component? J Hepatol 2014;61:1189-1191.

204. Schramm C, Herkel J, Beuers U, Kanzler S, Galle PR, Lohse AW. Pregnancy in autoimmune hepatitis: outcome and risk factors. Am J Gastroenterol 2006;101:556-560.

205. Werner M, Björnsson E, Prytz H, et al. Autoimmune hepatitis among fertile women: strategies during pregnancy and breastfeeding? Scand J Gastroenterol 2007;42:986-991.

206. Angelberger S, Reinisch W, Messerschmidt A, et al. Long-term follow-up of babies exposed to azathioprine in utero and via breastfeeding. J Crohns Colitis 2011;5:95-100.

207. Carbone M, Neuberger JM. Autoimmune liver disease, 
autoimmunity and liver transplantation. $J$ Hepatol 2014;60:210-223.

208. González-Koch A, Czaja AJ, Carpenter HA, et al. Recurrent autoimmune hepatitis after orthotopic liver transplantation. Liver Transpl 2001;7:302-310.

209. Chatrath H, Allen L, Boyer TD. Use of sirolimus in the treatment of refractory autoimmune hepatitis. Am J Med 2014;127:1128-1131.

210. Salcedo M, Vaquero J, Bañares R, et al. Response to steroids in de novo autoimmune hepatitis after liver transplantation. Hepatology 2002;35:349-356.

211. Georgiadou SP, Zachou K, Liaskos C, Gabeta S, Rigopoulou EI, Dalekos GN. Occult hepatitis B virus infection in Greek patients with autoimmune liver diseases. Liver Int 2009;29:434-442.

212. Rigopoulou EI, Zachou K, Gatselis N, Koukoulis GK, Dalekos GN. Autoimmune hepatitis in patients with chronic HBV and HCV infections: patterns of clinical characteristics, disease progression and outcome. Ann Hepatol 2014;13:127-135.

213. Azhar A, Niazi MA, Tufail K, Malek AH, Balasubramanian M, Araya V. A new approach for treatment of hepatitis $\mathrm{C}$ in hepatitis C-autoimmune hepatitis overlap syndrome. Gastroenterol Hepatol (N Y) 2010;6:233-236.

214. Ofori E, Ramai D, Ona MA, Reddy M. Autoimmune hepatitis in the setting of human immunodeficiency virus infection: A case series. World J Hepatol 2017;9:1367-1371.
215. Kia L, Beattie A, Green RM. Autoimmune hepatitis in patients with human immunodeficiency virus (HIV): Case reports of a rare, but important diagnosis with therapeutic implications. Medicine (Baltimore) 2017;96:e6011.

216. European Association for the Study of Obesity (EASO). EASLEASD-EASO Clinical Practice Guidelines for the management of non-alcoholic fatty liver disease. J Hepatol 2016;64:1388-1402.

217. Heimbach JK, Kulik LM, Finn RS, et al. AASLD guidelines for the treatment of hepatocellular carcinoma. Hepatology 2018;67:358-380.

218. Versini M, Jeandel PY, Rosenthal E, Shoenfeld Y. Obesity in autoimmune diseases: not a passive bystander. Autoimmun Rev 2014;13:981-1000.

219. Müller P, Messmer M, Bayer M, Pfeilschifter JM, Hintermann E, Christen U. Non-alcoholic fatty liver disease (NAFLD) potentiates autoimmune hepatitis in the CYP2D6 mouse model. J Autoimmun 2016;69:51-58.

220. De Luca-Johnson J, Wangensteen KJ, Hanson J, Krawitt E, Wilcox R. Natural history of patients presenting with autoimmune hepatitis and coincident nonalcoholic fatty liver disease. Dig Dis Sci 2016;61:2710-2720.

221. Weiler-Normann C, Lohse AW. Nonalcoholic fatty liver disease in patients with autoimmune hepatitis: Further reason for teeth GNASHing? Dig Dis Sci 2016;61:2462-2464. 


\section{Supplementary Table}

Supplementary Table 1 Grading of recommendations

\begin{tabular}{ll}
\hline I & Randomized controlled trials \\
II-1 & Controlled trials without randomization \\
II-2 & Cohort or case-control analytic studies \\
II-3 & Multiple time series, dramatic uncontrolled experiments \\
III & Opinions of respected authorities, descriptive epidemiology \\
\hline
\end{tabular}

Adapted from: [1] 